\title{
The potential role and trend of HIF-1 $\alpha$ in intervertebral disc degeneration: Friend or foe? (Review)
}

\author{
YONGJIN LI ${ }^{1-3^{*}}$, SHEN LIU ${ }^{1,2^{*}}$, DAYU PAN ${ }^{1,2^{*}}$, BAOSHAN XU ${ }^{3}$, XUEWU XING $^{4}$, HENGXING ZHOU $^{1,2}$, \\ BIN ZHANG ${ }^{1,2}$, SUZHE ZHOU ${ }^{5}$, GUANGZHI NING ${ }^{1,2}$ and SHIQING FENG ${ }^{1,2}$ \\ ${ }^{1}$ Department of Orthopedics, Tianjin Medical University General Hospital; ${ }^{2}$ Tianjin Neurological Institute, \\ Key Laboratory of Post-Neuroinjury Neuro-repair and Regeneration in Central Nervous System, \\ Ministry of Education and Tianjin City, Tianjin 300052; ${ }^{3}$ Department of Spine Surgery, Tianjin Hospital, Tianjin 300000; \\ ${ }^{4}$ Department of Orthopedic Surgery, First Central Clinical of Tianjin Medical University, Tianjin 300052; \\ ${ }^{5}$ Department of Orthopedics, The Affiliated Zhongshan Hospital of Fudan University, Shanghai 200034, P.R. China
}

Received October 16, 2018; Accepted November 8, 2019

DOI: $10.3892 / \mathrm{mmr} .2021 .11878$

\begin{abstract}
Lower back pain (LBP) is one of the most common reasons for seeking medical advice in orthopedic clinics. Increasingly, research has shown that symptomatic intervertebral disc degeneration (IDD) is mostly related to LBP. This review first outlines the research and findings of studies into IDD, from the physiological structure of the intervertebral disc (IVD) to various pathological cascades. The vicious cycles of IDD are re-described in relation to the analysis of the relationship among the pathological mechanisms involved in IDD. Interestingly, a 'chief molecule' was found, hypoxia-inducible factor- $1 \alpha$ (HIF-1 $\alpha$ ), that may regulate all other mechanisms involved in IDD. When the vicious cycle is established, the low oxygen tension activates the expression of HIF-1 $\alpha$, which subsequently enters into the hypoxia-induced HIF pathways. The HIF pathways are dichotomized as friend and foe pathways according to the oxygen tension of the IVD microenvironment. Combined with clinical outcomes and previous research, the trend of IDD development has been predicted in this paper. Lastly, an early precautionary diagnosis and treatment method is proposed whereby nucleus pulposus tissue for biopsy can be obtained through IVD puncture guided by B-ultrasound when the patient is showing symptoms but MRI imaging shows negative results. The
\end{abstract}

Correspondence to: Professor Guangzhi Ning or Professor Shiqing Feng, Department of Orthopedics, Tianjin Medical University General Hospital, 154 Anshan Road, Heping, Tianjin 300052, P.R. China

E-mail: ningguangzhi@foxmail.com

E-mail: sqfeng@tmu.edu.cn

*Contributed equally

Keywords: intervertebral disc degeneration, hypoxia-inducible factor-1 $\alpha$, nucleus pulposus, extracellular matrix, angiogenesis, apoptosis, matrix metalloproteinases, autophagy, inflammation, non-coding RNAs assessment criteria for biopsy and the feasibility, superiority and challenges of this approach have been discussed. Overall, it is clear that HIF-1 $\alpha$ is an indispensable reference indicator for the accurate diagnosis and treatment of IDD.

\section{Contents}

1. Introduction

2. HIF families

3. Vicious cycle pathways

4. Potential role of HIF-1 $\alpha$

5. HIF-1 $\alpha$ development trends

6. Conclusions

\section{Introduction}

Lower back pain (LBP) is one of the most common reasons for seeking medical advice in orthopedic clinics. World Health Organization statistics revealed that patients with LBP cost up to 100 billion dollars each year in the United States (1). According to a report, $68-85 \%$ of individuals worldwide experience $\mathrm{LBP}$ at least once in their lifetime (2) and 5\% ultimately go on to develop chronic LBP (CLBP) (3). This is associated with severe pain and disability, and is a heavy economic burden on society (4). Increasingly, studies have shown that one of the main symptoms associated with intervertebral disc (IVD) degeneration (IDD) is CLBP (5-8). A number of researchers have reported that genetic factors accounted for $>68 \%$ of the pathogenic factors that are associated with IDD, although a variety of factors can lead to IDD (9-11). IDD is the pathological basis of disc herniation, and it is likely to increase the susceptibility of disc herniation $(12,13)$. The spontaneous disappearance, or decrease in size, of a herniated disc in patients displaying clinical symptoms have been reported on numerous times in the past, but there has been an increasing number of cases, even in patients showing large herniated discs (14-16). One of the common features of these patients is that the individuals are relatively young and it was observed 
that herniated disc tissue retraction, or even disappearance through MRI (14-16). Recently, Gao et al (16) reported on a woman in her 40s whose herniated disc tissue self-absorbed 8 months after the initial diagnosis of lumbar disc herniation. This phenomenon cannot be explained by biomechanics. Therefore, exploring the mechanism of IDD from a genetic perspective is necessary in order to solve the current clinical problems of CLBP

Anatomically, the IVD consists of the central nucleus pulposus (NP) enriched in proteoglycans, the peripheral annulus fibrosus (AF), and the endplates of hyaline cartilage at the upper and lower ends (17). From the cross-section, IVD can be observed as four concentric areas: The outer AF; the inner AF; the transition zone; and the central NP (18). The IVD is essentially an avascular structure because vascular structures are only visible in the outer AF; they are not in NP tissue and these structures are separated by a thick layer of avascular AF (19). Blood vessels from the lumbar artery terminate at the cartilage endplate, with only a small amount of blood vessels infiltrating the cartilage endplate and the outer third of the AF zone, but none of these vessels penetrate the NP and inner AF $(17,20,21)$. NP cells (NPCs) are morphologically analogous to chondrocytes, and have similar histological and physiological structures to the articular cartilage (22). Therefore, NPCs are largely dependent on capillary diffusion through the cartilage endplates for oxygen exchange, nutrient acquisition and metabolic waste transport $(23,24)$. In addition to the complex structure, there is an oxygen concentration gradient around the avascular IVD where the partial pressure of oxygen in the IVD central region is as low as $1 \%(25)$. The oxygen partial pressure of degenerate tissue is lower than that of normal IVD tissue (26). Accumulating evidence has revealed that hypoxic environments play a crucial role in maintaining the physiological functions of IVDs, including cell metabolism and matrix synthesis (4,21,27-29). Therefore, NPCs adapt to survive in hypoxic microenvironments under physiological conditions (23). This hypoxic environment may affect the activity of a series of genes related to cell adaptation for survival in hypoxic microenvironments (24). Hypoxia-inducible factor- $1 \alpha(\mathrm{HIF}-1 \alpha)$ is one of the most essential transcriptional regulators of cell adaptation to hypoxic environments $(30)$. Feng et al $(28,29)$ found that the expression of HIF-1 $\alpha$ in human NPCs was significantly increased under hypoxic conditions compared with normoxic conditions. Richardson et al (31) demonstrated that HIF-1 $\alpha$ was markedly expressed in degenerative IVD tissue.

HIF- $1 \alpha$ is ubiquitously expressed in almost all cells in the human body. Benita et al (32) proposed that HIF-1 $\alpha$ has the potential to regulate 81 genes under hypoxic conditions in a number of cell types. It has also been found to play a vital role in the occurrence and progression of numerous diseases, including myocardial-cerebral ischaemia (33-35), tumours $(33,36)$ and chronic degenerative diseases $(4,21,29,37-39)$. IDD is identified as the most common chronic spinal degenerative disease; the pathogenesis of IDD is mainly related to the destruction of cells, in terms of both biochemistry and structure $(24,40)$. Thus far, the mechanisms of HIF- $1 \alpha$ in IDD have been widely reported. HIF-1 $\alpha$ is a marker of NPCs involved in: The synthesis and catabolism of the extracellular matrix (ECM) $(4,28,29,41)$; promoting angiogenesis (41,42); regulation of NPC apoptosis (43); inflammatory responses (41); provision of NPC energy metabolism $(31,44)$; modulation of NPC autophagy (45); NPC transplantation $(46,47)$; regulation of extracellular dystrophic calcification of NP (48); and regulation of the expression of matrix metalloproteinases (MMPs) (49-52). However, in addition, a comprehensive analysis of HIF-1 $\alpha$ in other tissues or cells found that HIF-1 $\alpha$ may also influence the occurrence and progression of IDD by participating in the process of spontaneous absorption of herniated disc tissue (52) and regulatory networks of non-coding RNAs (Tables I and II) (53). Despite extensive research in this area, the precise mechanism of IDD remains mostly unknown. Therefore, this article summarizes the reported findings on the potential role and possible mechanisms of HIF-1 $\alpha$ in IDD, as well as predicting the trends in development. Moreover, an early precautionary diagnosis and treatment method has been proposed.

\section{HIF families}

HIFs belong to the Per-Arnt-Sim family; they are heterodimeric proteins composed of $\alpha$ and $\beta$ subunits. The $\alpha$ subunit predominantly determines the activity of HIF, which is regulated by the oxygen-dependent degradation (ODD) domain in its central region, and thus can regulate gene expression depending on the level of oxygen tension (54). The $\beta$ subunit is expressed in the nucleus, where it has roles in maintaining the stability of HIF structure and biofunctions, but it is not regulated by oxygen tension (55). There are three isoforms of HIF- $\alpha$, HIF-1 $\alpha$, HIF-2 $\alpha$ and HIF-3 $\alpha$ (56-58). HIF-1 $\alpha$ and HIF- $2 \alpha$ have similar mechanisms of action in different cell types because they have extensive sequence homology and contain two ODD domains (56). Therefore, they are closely related to each other and can activate gene transcription that is dependent on the hypoxia responsive elements (HREs) (56). HIF-3 $\alpha$ has a unique structure, containing only one ODD domain; it is spliced selectively and modulated via HIF-1 $\alpha$ (57,58). A number of studies have shown that the metabolism of HIF- $\alpha$ is associated with oxygen concentration in numerous cell types $(33,34,36)$. Under normoxic conditions, the $\alpha$ subunit is hydroxylated and subsequently activates prolyl hydroxylase (PHD), which is then rapidly degraded via the ubiquitin-proteasome pathway (33). However, when the cells are exposed to hypoxic-ischaemic conditions, PHD activity is reduced and the degradation of the $\alpha$ subunit is inhibited $(33,59)$. Thus, HIF-1 $\alpha$ rapidly expands and gradually accumulates in the cytoplasm $(33,59)$. Then, it enters the nucleus and binds to HIF-1 $\beta$ to form an ectopic dimer, HIF-1, which recognizes and binds to the conserved sequence of HREs to activate the transcription of target genes (60). The $\alpha$ subunits of HIF- $1 \alpha$ and HIF- $2 \alpha$ have non-overlapping regions that have different biofunctions and even completely converse effects. Firstly, HIF-1 $\alpha$ is ubiquitously expressed in almost all cells in the human body, while HIF- $2 \alpha$ appears to be expressed in specific tissues, mainly the lung, heart, kidneys and liver in adults $(61,62)$. Secondly, HIF-1 $\alpha$, but not HIF-2 $\alpha$, has been shown to markedly regulate the expression of the key enzymes involved in the glycolytic pathway (44). Furthermore, HIF-1 $\alpha$ exclusively regulates adenosine triphosphate (ATP) production and mediates macrophage migration, infiltration and bacterial 

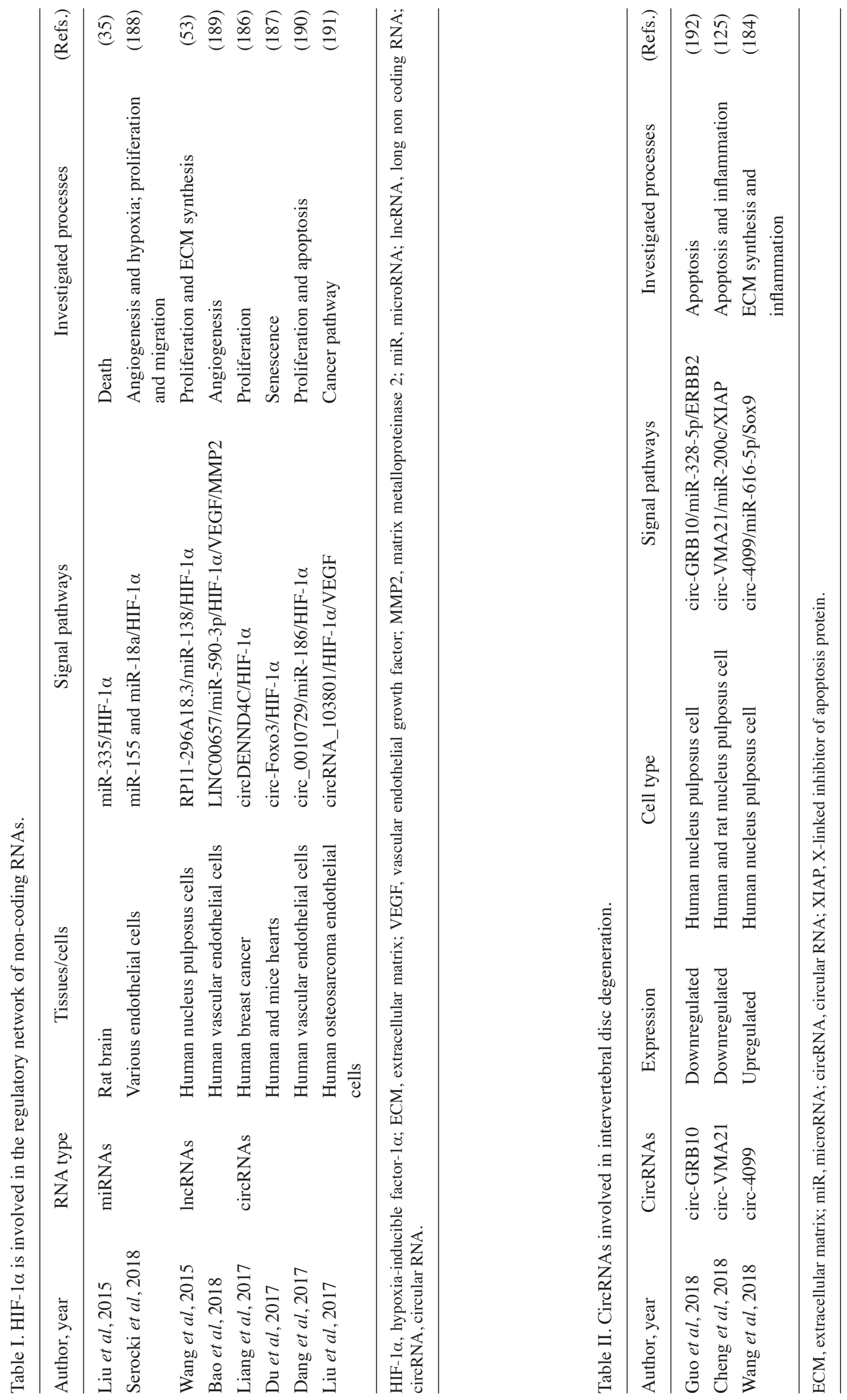


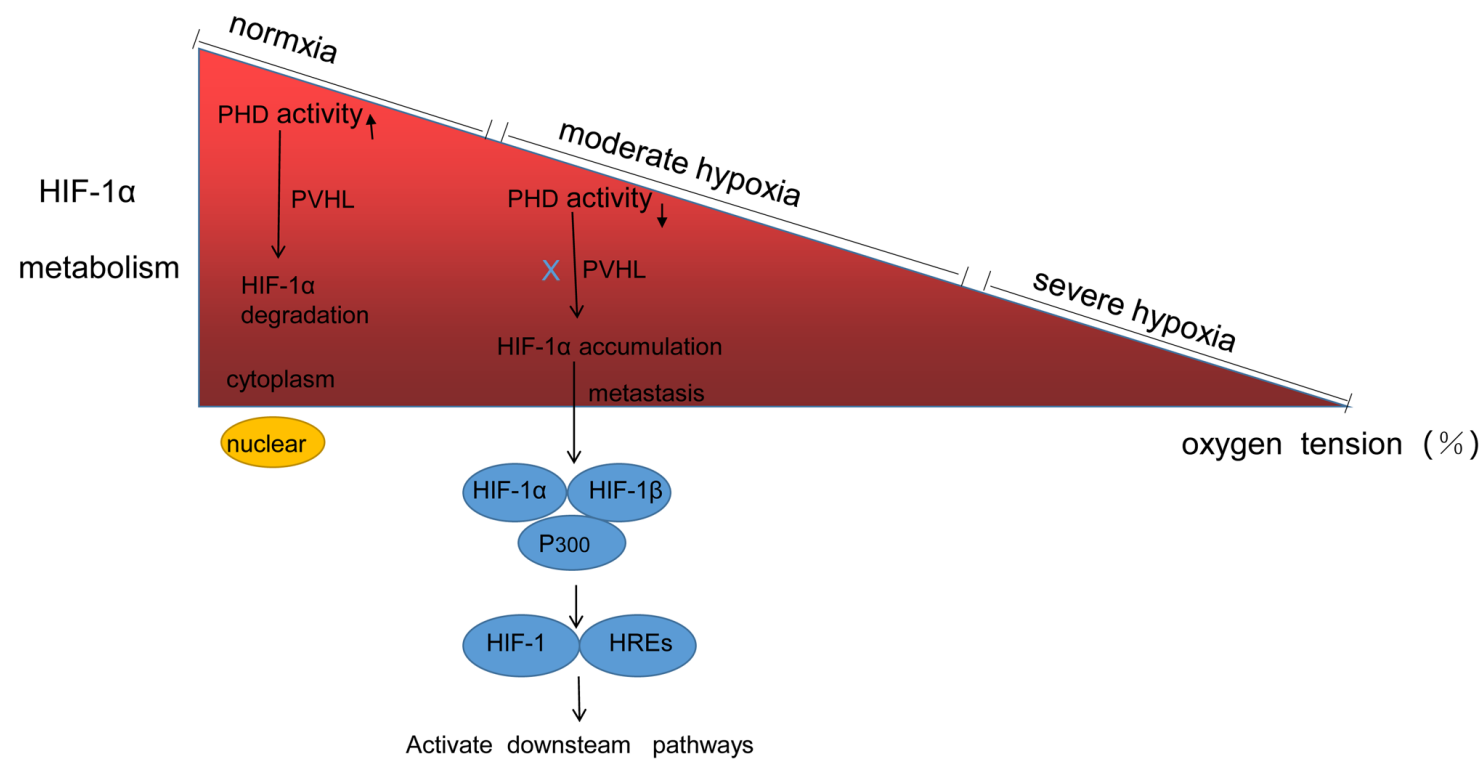

Figure 1. HIF-1 $\alpha$ metabolism. HIF-1 belongs to the Per-Arnt-Sim family, heterodimeric proteins composed of $\alpha$ and $\beta$ subunits. Under normoxia, the $\alpha$ subunit is hydroxylated and subsequently activates PHD, which is then degraded HIF-1 $\alpha$ via pVHL. However, the PHD activity is reduced during moderate and severe hypoxia, following which the degradation of the $\alpha$ subunit is inhibited, so HIF-1 $\alpha$ gradually accumulates in the cytoplasm. HIF-1 $\alpha$ then enters the nucleus and binds to HIF-1 $\beta$ to form an ectopic dimer, HIF-1, which recognizes and binds to HREs to activate the downstream target genes. HIF-1 $\alpha$, hypoxia-inducible factor-1 $\alpha$; PHD, prolyl hydroxylase; HREs, hypoxia responsive elements; pVHL, protein von HippeI-Lindau.

killing during acute inflammation responses, while HIF-2 $\alpha$ mainly mediates tumour-associated inflammation and appears to play a greater role than HIF-1 $\alpha$ in cytokine production (63). Thirdly, the metabolism of HIF- $1 \alpha$ and HIF-2 $\alpha$ in NPCs is also different. PHD family members include PHD1, PHD2 and PHD3 (64). The degradation of HIF-1 $\alpha$ and HIF-2 $\alpha$ is mainly mediated by the $26 \mathrm{~S}$ proteasome, which is not associated with oxygen tension (65). In addition, HIF-1 $\alpha$ is mainly degraded by the oxy-PHD2 pathways, whereas the degradation of HIF-2 $\alpha$ is associated with PHD3 pathways $(21,65)$. Lastly, HIF-1 $\alpha$ has an antitumour effect, but HIF-2 $\alpha$ mainly promotes tumour progression $(44,66)$. Therefore, it is more meaningful to study the mechanism of HIF-1 $\alpha$ in IDD, and the metabolism of HIF-1 $\alpha$ is shown in Fig. 1.

\section{Vicious cycle pathways}

It is generally hypothesized that disrupting the diffusion of oxygen, nutrients and metabolic waste in the IVD space is the most critical mechanism in the occurrence and progression of IDD $(24,67)$. With the occurrence of IDD, the amount of water in the NP tissue is reduced, following which the diffusion of oxygen, nutrients and metabolic waste is restricted. The oxygen tension is lower in the IVD microenvironment in the wake of poor diffusion, following which the production of lactate is increased through anaerobic metabolism (24). The excretion of lactate is blocked so it gradually accumulates, decreasing the $\mathrm{pH}$ of the IVD microenvironment, which further affects cellular metabolism and biofunction (24). Thus, NPC quantity and viability is decreased, and the synthesis and decomposition of ECM are unbalanced; this imbalance decreases the intradiscal pressure, transforms the biomechanics from hydrostatic stress to shear stress and decreases the IVD height, which further aggravates the progression of IDD $(24,40)$. Therefore, the first important vicious cycle is established. The low oxygen tension activates the expression of HIF-1 $\alpha$, which subsequently enters into the hypoxia-induced HIF pathways (Fig. 2). The HIF pathways are dichotomized as friend and foe pathways according to the oxygen tension of the IVD microenvironment (Figs. 3 and 4).

The second vicious cycle centers on cartilage endplate calcification (CEC). A previous study indicated that the degree of CEC is associated with the severity of IDD (68). When the water content in NP tissue decreases, pyknotic substances are deposited in the cartilage endplate, which gradually calcifies; the permeability of cartilage endplate declines and then enters into the vicious cycle (Fig. 2) $(25,69)$. Notably, there is an association between angiogenesis and CEC, but the mechanism by which angiogenesis aggravates CEC remains unclear (70).

\section{Potential role of HIF-1 $\alpha$}

ECM metabolism. An IVD is a fibrous cartilage pad between the vertebral bodies that resists pressure from the spine and allows for slight movement of the spine (71). Peripheral AF cells and central NPCs from IVDs exhibit different morphology and functional expression. AF cells are similar to fibroblasts in morphology and contain higher levels of collagen type I (COL1), which accounts for $\sim 68 \%$ of the dry weight of AF $(67,71,72)$. NP is enriched in collagen type II (COL2) and proteoglycans; COL2 accounts for $\sim 20 \%$ of the dry weight of NP, and aggrecan (ACAN) is the major component of proteoglycans, which constitute $50 \%$ of the wet weight of NP $(22,71,72)$. ACAN contains a large quantity of chondroitin sulfate (CS), which primarily binds to water molecules and is responsible for maintaining the moisture and mechanical load of IVD; it is necessary for IVD to exert its physiological functions and bear stress (73-75). Collagen imparts tensile strength to IVD by forming a network of collagen fibres that encloses the proteoglycans (72). Therefore, it is more 


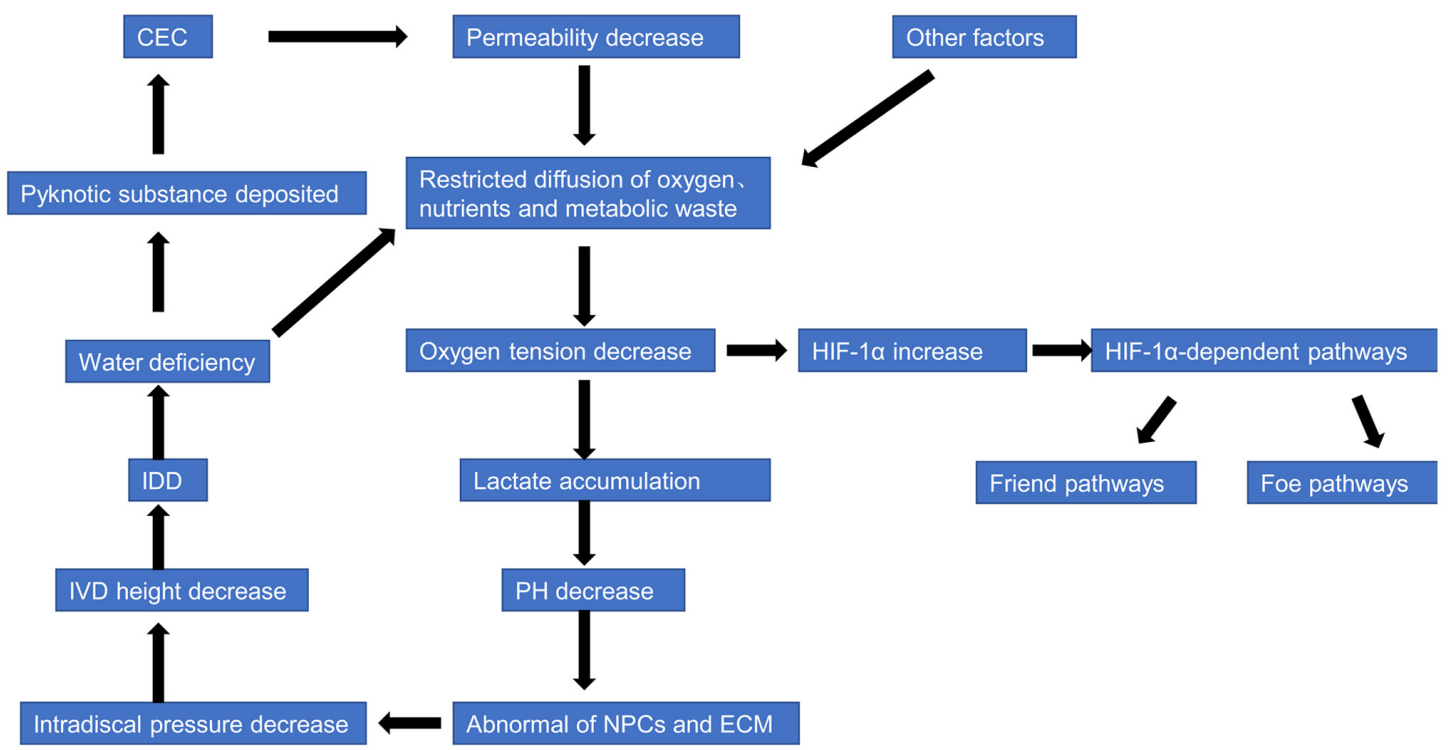

Figure 2. Vicious cycle pathways. The center of the vicious cycle pathways is restricted diffusion of oxygen, nutrients and metabolic waste. Two critical factors contributing to these restrictions are the decrease of cartilage endplate permeability and water deficiency of IVD. The oxygen tension is lower in the IVD microenvironment as a result of poor diffusion. This low oxygen tension establishes the vicious cycle pathways and promotes the expression of HIF-1 $\alpha$, which subsequently enters into the hypoxia-induced HIF pathways. The HIF pathways are dichotomized as friend and foe pathways according to the oxygen tension. IVD, intervertebral disc; HIF-1 $\alpha$, hypoxia-inducible factor-1 $\alpha$; CEC, cartilage endplate calcification; IDD, IVD degeneration; NPC, nucleus pulposus cells; ECM, extracellular matrix.

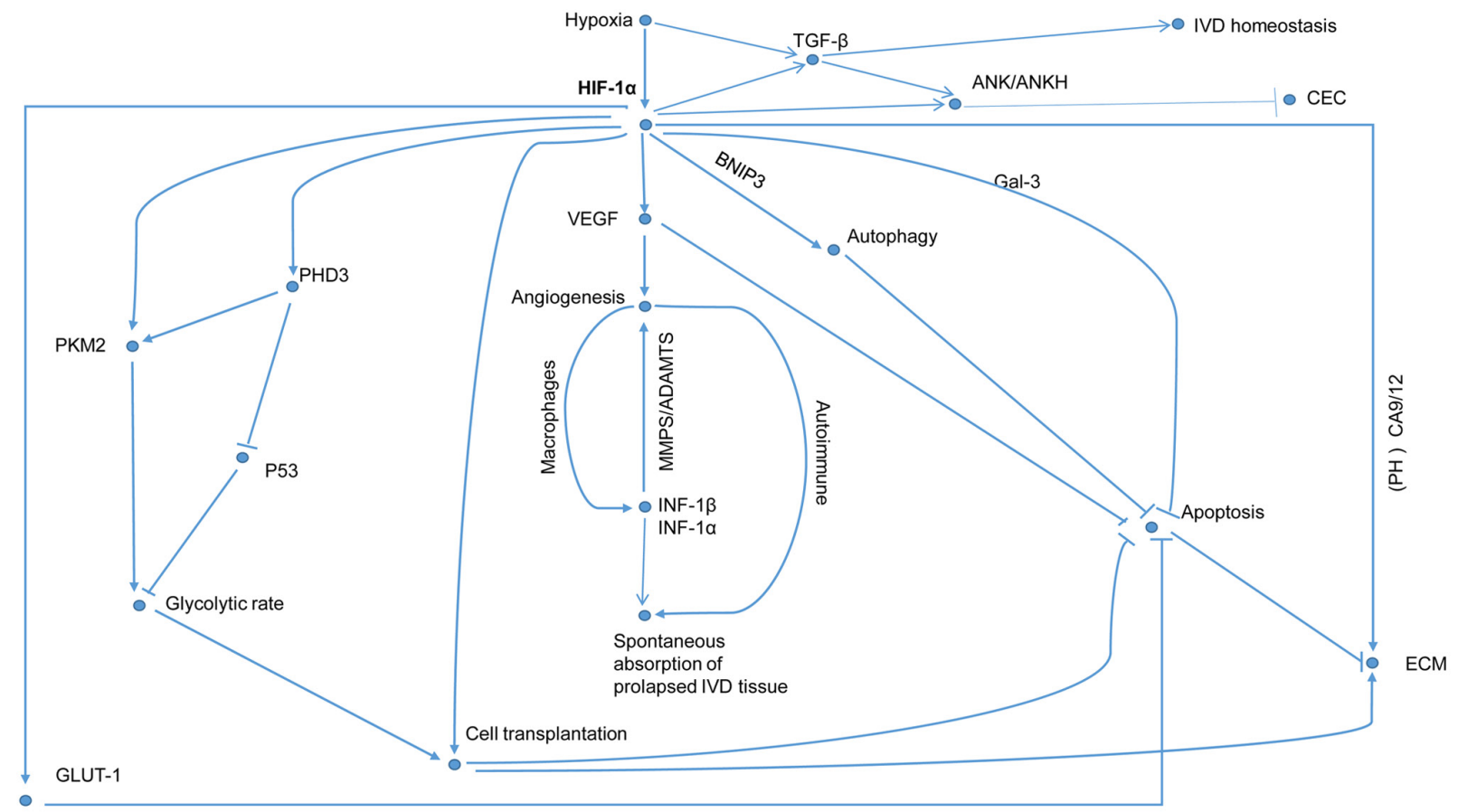

Figure 3. Friend pathways. During moderate hypoxia, the friend role of HIF-1 $\alpha$ is increasingly reinforced as oxygen tension gradually decreases. There are a number of pathways in this process, but the end point is the upregulation of ECM synthesis. HIF-1 $\alpha$, hypoxia-inducible factor-1 $\alpha$; ECM, extracellular matrix; PKM2, pyruvate kinase M2; GLUT-1, glucose transporter 1; PHD3, prolyl hydroxylase 3; VEGF, vascular endothelial growth factor; INF-1, eukaryotic initiation factor 4A; MMPS, matrix metalloproteinases; ADAMTS, a disintegrin and metalloproteinase with thrombospondin motifs; BNIP3, BCL2 interacting protein 3; TGF- $\beta$, transforming growth factor- $\beta$; IVD, intervertebral disc; ANK/ANKH, progressive ankylosis; Gal-3, galectin 3; CEC, cartilage endplate calcification; CA, carbonic anhydrase.

meaningful to study NPCs than AF cells. Interestingly, the content and distribution of various collagens changes with IDD, while IVD ageing will not cause this change. In the early stages of degeneration, collagen content usually increases in the region of its distribution (76,77). COL1 begins to appear in the nucleus, and collagen types IV and $\mathrm{X}$ can be detected with the aggravation of IDD; the expression of COL2 was not detected in the endplate (76,77). Accumulating evidence suggests that ECM plays an important role in supporting the NP-integrated structure and biofunctions, as well as mediating 


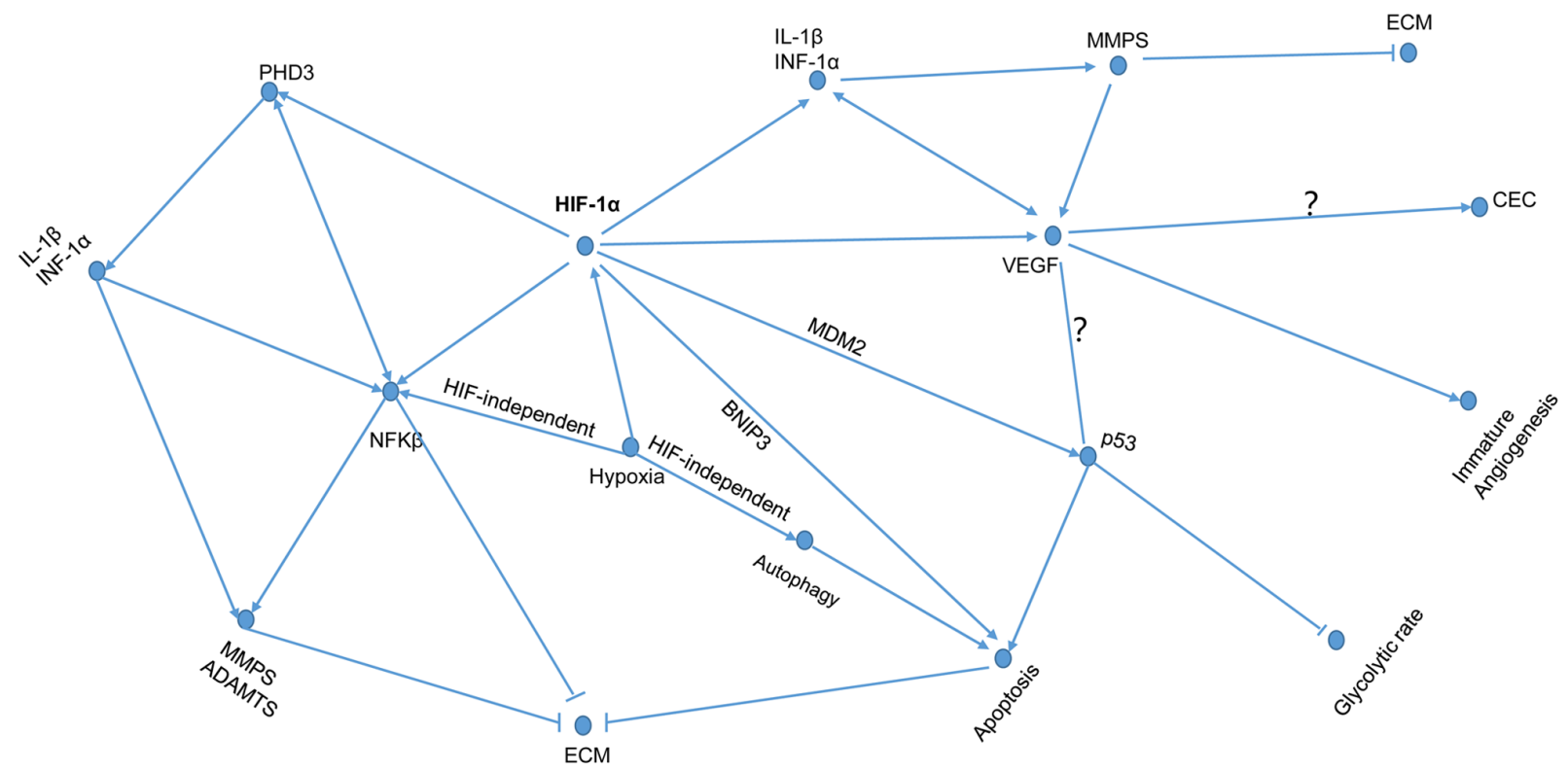

Figure 4. Foe pathways. During severe hypoxia, the foe role of HIF-1 $\alpha$ is increasingly reinforced as the oxygen tension gradually decreases. HIF-1 $\alpha$, hypoxia-inducible factor-1 $\alpha$; IL, interleukin; PHD3, prolyl hydroxylase 3; INF-1, eukaryotic initiation factor 4A; MMPS, matrix metalloproteinases; ADAMTS, a disintegrin and metalloproteinase with thrombospondin motifs; ECM, extracellular matrix; BNIP3, BCL2 interacting protein 3; MDM2, mouse double minute 2 homolog; NFK $\beta$, nuclear factor $\kappa \beta$; VEGF, vascular endothelial growth factor; $C E C$, cartilage endplate calcification.

NP tissue morphogenesis, homeostasis, repair and remodelling $(25,77,78)$. A number of factors cause the degradation and decreased synthesis of the ECM, leading to a downregulation in the water content of NP tissue; thus, the IVD height and the capability of bearing mechanical loads decrease further, which will ultimately trigger IDD (79).

Hypoxia significantly increased the phenotype of NPCs while having little effect on AF, indicating that HIF- $1 \alpha$ can be used as marker of NPCs $(28,29)$. Richardson et al (31) found that HIF-1 $\alpha$ is expressed in NPCs rather than AF cells, further demonstrating that the use of HIF-1 $\alpha$ for phenotypic identification of NPCs is scientific and justified. However, there is still controversy surrounding the findings concerning the regulation of ECM metabolism by HIF-1 $\alpha$. Over the years, an increasing number of studies have shown that hypoxia can induce numerous cells to upregulate HIF- $1 \alpha$ to promote ECM synthesis, including NPCs $(4,28,29,80)$, chondrocytes (81-83), fibroblasts (84) and mesenchymal stem cells (83). Animal and human studies have suggested that the content of ECM synthesis has a negative association with the degree of hypoxia (Figs. 3 and 4) $(28,29,85-87)$. The ideal level of hypoxia for reinforcing NPC survival is $1 \%$ physiological oxygen concentration (85). Ishihara and Urban (87) reported that the synthesis of glycosaminoglycan (GAG) in bovine NPCs significantly increased as the oxygen tension in the medium gradually decreased. Furthermore, Liu et al (80) found that HIF-1 $\alpha$ increases the expression of COL2 and ACAN via the mediation of the NOTCH1 signalling pathway. Interestingly, however, Cigognini et al (88) found that although HIF-1 $\alpha$ was activated at 2\% oxygen tension, no increase in ECM synthesis was observed, which suggested that HIF-1 $\alpha$ is not the only factor that promotes ECM synthesis. Another study showed that $\mathrm{O}_{2}$ is essential for the synthesis of GAG in bovine NPCs (89). In complete anaerobic conditions, bovine NPCs express little GAG (89). These two different results may be attributed to different cell-specific endogenous factors, including age, sex, histologic origin and the severity of the damage model (88). Exploring and analysing the ways in which HIF-1 $\alpha$ promotes or inhibits ECM synthesis in NPCs, and finding the most critical mechanism for regulating HIF-1 $\alpha$ should be the focus of future research.

Angiogenesis. The process of forming new capillaries from existing blood vessels is called angiogenesis (90). Vascular endothelial growth factor (VEGF) is the most important factor in angiogenesis (91). VEGF regulates vascular maturation (92), alters ECM expression (93), increases vascular permeability (94), promotes endothelial cell proliferation and maintains vascular function (94). The oxygen tension of the cell survival environment is an important factor in the regulation of VEGF expression and angiogenesis (41). Hypoxia can stabilize the post-transcriptional levels of HIF- $1 \alpha$, and HIF-1 $\alpha$ directly induces VEGF expression under hypoxic conditions $(41,95,96)$. HIF1- $\alpha$ can also indirectly regulate VEGF expression via modulating its own transcriptional activity through E/D-rich carboxy-terminal domain-2 (a p300 binding protein) (97). In addition, interleukin (IL)-8 (98), basic fibroblast growth factor (bFGF) $(99,100)$ and transforming growth factor- $\beta$ (TGF- $\beta$ ) (100) also have strong angiogenic effects, and these factors are downstream target genes of HIF-1 $\alpha$. TGF- $\beta$ also activates bFGF and maintains IVD homeostasis $(101,102)$. Interestingly, TNF- $\alpha(103,104)$, IL-1 $\beta(41,105)$ and MMPs $(106,107)$ also play important and complex roles in the regulation of angiogenesis. In endothelial cells, TNF- $\alpha$ promotes angiogenesis by increasing the expression of VEGF, IL-8 and bFGF (103). MMP-2 may promote angiogenesis, whereas MMP-9 may block angiogenesis by converting plasminogen into an angiogenesis inhibitor $(106,107)$. It is noteworthy that hypoxia has a dual role in angiogenesis to avoid over-activation of the HIF-1 $\alpha /$ VEGFA axis during 
hypoxia in order to maintain the surrounding environment and biofunction of cells (108).

Studies have indicated that HIF-1 $\alpha$ and VEGF are directly involved in the entire process of angiogenesis (109). The VEGF gene may increase the susceptibility to IVD degeneration, and VEGF expression is also positively correlated with the severity of IVD degeneration (110). With regard to the role of angiogenesis in IDD, different scholars hold different perspectives. Some scholars hypothesize that angiogenesis may be the adaptive response of the body to deal with various stresses or injuries to repair degenerative IVD tissue (Fig. 3). Long et al (111) found that the expression of VEGF in human IVD tissues is time-specific, and that there is differential expression in different developmental stages of IVD. This is clearly related to the observation that IVD undergoes partial vascularization, devascularization and revascularization (111). Vascularized IVD tissue not only increases blood circulation and improves the nutrition of NPCs, but also plays an important role in the spontaneous absorption of prolapsed IVD tissue $(104,107,112)$. Neovascularization facilitates the infiltration of inflammatory cells, such as macrophages, into NP tissues $(9,112,113)$. The prolapsed IVD tissue can be phagocytosed by macrophages or dissolved via autoimmune reactions $(112,113)$. Various cytokines, such as TNF- $\alpha$ and IL-1 $\beta$, can also be synthesized by macrophages and other cells to promote both MMPs and a disintegrin and metalloproteinase with thrombospondin motifs (ADAMTS), in order to digest ECM components of prolapsed tissues to mitigate IDD $(112,113)$. Activated MMPs can stimulate VEGF expression and promote the vascularization of IVD (107). Other scholars hypothesize that angiogenesis may accelerate IDD (Fig. 4). Uncontrolled and immature angiogenesis is the cause of a variety of diseases (89). Although HIF-1 $\alpha$ promotes angiogenesis, it may promote immature angiogenesis to trigger IDD. VEGF may have a combinatory effect with the $p 53$ gene to promote IDD (114). p53 induces apoptosis by directly combining with HIF-1 $\alpha$ (115) and is ubiquitously considered a pro-apoptotic gene (116). The association between HIF-1 $\alpha$ and p53 is so complex that it has not been elucidated, but it is clear that p53 is motivated by HIF-1 $\alpha$ to reduce glycolytic rates under severe or chronic hypoxia (36). Pyruvate kinase M2 (PKM2) reinforces the transactivation of HIF-1 $\alpha$ and glycolytic rates via interaction with PHD3 (117). It could be that HIF-1 $\alpha$ safeguards p53 against degradation via mouse double minute 2 homolog (MDM2) (81). Furthermore, in mild hypoxic conditions, HIF-1 $\alpha$ degradation of p53 is associated with PHD3, while MDM2 is not involved in this process (118). Interestingly, p53-enhanced HIF-1 $\alpha$ ubiquitination and degradation is involved in the malfunction of cell mitochondria (119). PHD3 is a critical regulator of HIF-1 $\alpha$, p53 and $\mathrm{NF}-\kappa \mathrm{B}$ pathways $(9,21,118,120)$. HIF-1 $\alpha$ upregulates the expression of PHD3, while PHD3 consolidates the transcriptional activity of HIF-1 $\alpha$ (21). PHD3 upregulates the TNF- $\alpha$-induced NF- $\kappa$ B/p65 signaling activity to reinforce the expression of ADAMTS-5 and MMP-13; additionally it can downregulate the expression of the genes $A C A N$ and COL2 (9,121). Fujita et al (120) first showed that the expression of PHD3 is mediated by $\mathrm{NF}-\kappa \mathrm{B}$-dependent, but not HIF-1 $\alpha$-dependent inflammatory cytokines in NPCs. PHD3 decreases the activity of $\mathrm{p} 53$, playing a crucial role in the reciprocal negative correlation between the p53 and $\mathrm{NF}-\kappa \mathrm{B}$ pathways (118). Another possible mechanism is that activated MMPs and ADAMTS may digest ECM components in non-prolapsed IVD tissues (111). In addition, angiogenesis can also aggravate IDD by promoting CEC (113).

Inflammation. During IDD, the accompanying aseptic inflammatory response within the NP is another important pathological phenomenon (121). The expression of a number of pro-inflammatory cytokines secreted by IVDs and other cells, such as TNF- $\alpha(8,74,121)$, IL-1 $\beta(8,74,121-125)$ and IL-6 (121) are upregulated in IDD. These cytokines promote the progression of IDD by increasing the expression of MMPs $(8,40,125)$, degrading ECM $(8,74,125)$, promoting angiogenesis (103-105), enhancing NPC apoptosis (123-125) and deteriorating IVD tissue (Fig. 4) (8). IL-1 $\beta$ is considered to be the most important cytokine involved in multiple pathological processes of IDD $(8,122)$. IL-1 $\beta$ and TNF- $\alpha$ can reduce the biosynthesis of ECM (including CS, COL2 and ACAN), and enhance the expression of MMPs and pro-apoptotic proteins by stimulating non-coding RNAs $(74,125,126)$. Additionally they can also upregulate the expression of ADAMTS-4/5 to enhance ECM degradation through MAPK and NF- $\kappa$ B signaling pathways $(8,125,127)$. Interestingly, they also activate the Notch pathway to maintain NPC homeostasis by mediating MAPK and $\mathrm{NF}-\kappa \mathrm{B}$ signaling pathways (128). In addition, IL-1 $\beta$ induces NPC apoptosis and autophagy through the mitochondrial pathway, as well as activating the $\mathrm{NF}-\kappa \mathrm{B}$ signaling pathway to promote NPC apoptosis, and inhibit the expression of ACAN and COL2 (123-125). Notably, Risbud and Shapiro (8) elucidated that there are three distinct but overlapping inflammation response stages in IDD, of which the second stage emphasizes the role of angiogenesis in transporting various inflammatory cytokines into IVD tissue to further amplify the inflammatory responses that were established in the first stage. Here, we propose a hypothesis that HIF-1 $\alpha$ may be predominantly involved in the second stage to regulate the inflammation response of the IVD microenvironment (129).

Increasingly, research suggests that there is a sophisticated and tight relationship between hypoxia, HIF-1 $\alpha$, inflammation and angiogenesis (Fig. 4) (39,130). The NF- $\kappa \mathrm{B}$ cascade is an inflammatory signaling pathway. Hypoxia activates both the canonical HIF-dependent pathway and the NF- $\kappa \mathrm{B}$ signaling pathway by enhancing inhibitor of $N F-\kappa B$ kinase subunit $\beta$ (IKK $\beta$ ) activity (an NF- $\mathrm{NB}$ inhibitor) and decreasing PHD-dependent hydroxylation, as IKK $\beta$ contains sequences that are similar to hydroxylation sites for binding of PHD to HIF-1 $\alpha(39,130)$. Notably, IKK $\beta$ is also potentially hydroxylated by PHD on account of its particular structure (39). From this perspective, HIF- $1 \alpha$ is involved in activating the $\mathrm{NF}-\kappa \mathrm{B}$ signalling pathway (130). Moreover, NF- $\kappa \mathrm{B}$ also stabilizes HIF-1 $\alpha$ expression under normoxic conditions and activates HIF-related pathways (39,130). Konisti et al (39) and Oliver et al (130) demonstrated the interaction between the $\mathrm{NF}-\kappa \mathrm{B}$ signalling pathway and HIF-related pathways, which together induce and amplify the inflammatory cascade, and also promote angiogenesis. Previously, it has been confirmed that the expression of HIF-1 $\alpha$ is upregulated in inflammatory diseases, such as osteoarthritis $(37,131)$ and rheumatoid arthritis $(37,39,131)$. In 2003, Cramer et al (129) conditionally knocked out HIF-1 $\alpha$ in mouse bone marrow cells, and found 
that the production of ATP and biofunction of macrophages decreased significantly, thus further demonstrating that HIF-1 $\alpha$ controls the inflammatory response via regulating the glycolytic metabolic pathway and plays a key role in the early stage of inflammatory cell infiltration. Subsequently, in 2010 , Imtiyaz et al (63) found that the production of ATP is exclusively regulated via HIF-1 $\alpha$, but not HIF-2 $\alpha$. Firstly, NPCs survive in a hypoxic microenvironment, and the expression of HIF-1 $\alpha$ is upregulated in IDD $(23,28,29)$. Secondly, NPCs are primarily powered via the anaerobic glycolysis pathway (132). Finally, IDD is often accompanied by aseptic inflammatory response in NPCs (122). Therefore, in this article it is hypothesized that the hypoxia-HIF-inflammatory pathway is involved in the regulation of IDD. Further investigation is needed to elucidate the above hypothesis.

MMPs. MMPs are endopeptidases of the ECM that have the ability to degrade almost all known components of the ECM in IVDs $(133,134)$. Structurally, MMPs can be divided into six main sections: Gelatinase (MMP-2 and MMP-9); collagenase (MMP-1, MMP-8, MMP-13 and MMP-18); matrix degradation element (MMP-3, MMP-10 and MMP-11); matrilysins (MMP-7 and MMP-26); transmembrane and GPI-linked MT-MMP (MMP-14, MMP-15, MMP-16, MMP-17, MMP-24 and MMP-25); and glassy lectin (MMP-21), as well as other types of MMPs (MMP-24) (133,135-137). Functionally, a variety of studies have shown that different types of MMPs, including MMP-2 (134,138-142), MMP-9 (134,139,143), MMP-13 (144), MMP-14 (145) and MMP-16 (146) are negatively correlated with the ECM level of degenerated NP and can promote IDD via the induction of ECM degradation. The most studied MMP is MMP-2, and upregulation of its expression is significantly associated with IDD (137-140). As early as 1997, Crean et al (134) found that the expression levels of MMP-2 and MMP-9 were related to the extent of IVD degeneration. Kozaci et al (138) found that MMP-2 was upregulated in the early stages of degenerative disc disease, and could promote IDD by degrading COL2. Roberts et al (139) found that the expression of MMPs was the most abundant in blood vessels and cell clusters of degenerative IVDs, and was associated with the grade of IDD on the macroscopic level. Rutges et al (140) reported that increased MMP-2 activity during disc degeneration was associated with MMP-14 expression. Micro (mi)RNAs are a class of small non-coding RNA regulators. A number of miRNAs have distinct expression profiles in human normal and degenerative IVDs $(143,144)$. They promote the apoptosis or ECM degradation of NPCs in IVD to regulate IDD progression via the targeted regulation of MMPs $(144,145)$. Xu et al (143) found that miRNA-133a was involved in the regulation of IVD degeneration by negatively regulating the expression of MMP9 indirectly, and outlined the role of the miRNA-133a/MMP9/COL2 axis in the pathophysiology of IDD. Ji et al (145) demonstrated that miRNA-193a-3p may participate in disc degeneration via the targeted regulation of MMP-14. Zhang et al (146) reported that miRNA-155 inhibits the ECM degradation of NP and reverses IVD degeneration by targeting negative regulation of MMP-16 expression. At the same time, MMP-16 is involved in MMP-2 activation (147). The expression of MMP-2 was upregulated by HIF-1 $\alpha$ in numerous cell types $(49-52,148)$. Wu et al (52) found that the expression of HIF-1 $\alpha$ and MMP-2 increased in degenerated lumbar IVD, and that there was a significant association between them. Therefore, in the present review, it is hypothesized that HIF-1 $\alpha$ may also increase MMP-2 activity in degenerated NPCs. However, the mechanism by which HIF-1 $\alpha$ promotes MMP-2 expression remains unclear. Inflammatory cytokines such as IL-1 $\beta(121,149)$ and TNF- $\alpha(121,142,149)$ stimulate the expression of MMP-2 in the degenerative tissues of IVD. In summary, it is hypothesized that the HIF-1 $\alpha /$ IL-1 $\beta$ and TNF- $\alpha /$ MMP-2/ECM axes may play an important role in the development of IDD (Fig. 4).

Energy metabolism. NPCs are mainly dependent on anaerobic glycolysis to synthesize ATP to maintain energy metabolism in the absence of oxygen (132). HIF-1 $\alpha$ regulates ATP production and can be involved in the regulation of glycolytic metabolism by stimulating the expression of glycolytic genes $(43,63,129)$. Glucose transporter (GLUT), located on the cell membrane, assists cells to take up glucose and plays an important role in glycolysis $(31,150-152)$. There are numerous subunits of GLUT, of which GLUT-1 is the most widely studied in IDD. It has been shown that the overexpression of GLUT-1 reduced hypoxia-induced apoptosis (151). In addition, GLUT-1 provides energy for transplanted cells under hypoxia (Fig. 3) (150). Richardson et al (31) found that the expression of GLUT in NPCs is positively correlated with the expression of HIF- $1 \alpha$ and the severity of IDD. The upregulation of HIF-1 $\alpha$ increased the expression of GLUT-1, GLUT-3 and GLUT-9 in NPCs; however, this association has not been observed in AF cells (31). Furthermore, HIF-1 $\alpha$ is involved in regulating the expression of a series of genes in the anaerobic glycolysis pathway, such as 6-phosphofructo-2-kinase (152), PKM2 (117), phosphoglycerate kinase-1 (119) and lactate dehydrogenase (119). HIF-1 $\alpha$ is also involved in regulating mitochondrial energy metabolism $(153,154)$. Papandreou et al (154) found that HIF- $1 \alpha$ also activates pyruvate dehydrogenase kinase- 1 in hypoxia and thereby inhibits mitochondrial function. In addition, HIF- $1 \alpha$-induced mitochondrial autophagy decreases the quantity of mitochondria to reduce oxygen consumption (155). However, non-mitochondrial oxygen consumption was found to be regulated via protein-tyrosine phosphatase-1B in breast cancer under hypoxia (156). Whether HIF-1 $\alpha$ is involved in the above process remains unknown.

Autophagy. Autophagy is a non-apoptotic, programmed cell death that leads to the self-digestion and degradation of unwanted proteins and organelles to prevent cellular stress and maintain cell function (157). Cells can resist apoptosis and senescence by activating autophagy, which alleviates the progression of certain chronic degenerative diseases (158-162). Autophagy plays a crucial role in the pathogenesis of a number of degenerative diseases, including osteoarthritis (158) and IDD (159-162). The autophagy-related genes or proteins beclin 1, cathepsin B, damage-regulated autophagy modulator 1 and p65 were highly expressed in degenerated IVD tissues compared with normal, healthy IVD tissues (163). Autophagy is a physiological response to hypoxia in cells, and has a complicated relationship with hypoxia $(164,165)$. HIF-dependent autophagy enhances cell survival during physiological hypoxia or mild hypoxia (Fig. 3), while autophagy 
reinforces cell death via a HIF-independent pathway in severe hypoxia or even anoxia (Fig. 4) (164). Accumulating evidence indicates that HIF-1 $\alpha$ induces autophagy via the activation of BCL2 interacting protein 3 (BNIP3) in different mammalian cell types $(155,164,166,167)$. Follicle-stimulating hormone can induce autophagy of mouse granulosa cells through the AKT-mTOR signalling pathway, and HIF-1 $\alpha$ is a key factor in mediating this process (167).

The level of cellular autophagy changes accordingly as IVD degenerates and ages $(160,164,168)$. There has been preliminary progress in the study of whether HIF-1 $\alpha$ regulates IDD through autophagy in IVD cells under hypoxic conditions. On the one hand, Ye et al (168) found that the level of autophagy in rat NP tissues increased with age, and the level of autophagy was higher in the IDD model group compared with the control group. A number of studies have shown that NPCs exhibit lower autophagy activity in culture under hypoxia than in normoxia, which is contrary to studies in most other types of cells $(45,164,168)$. Considering the special physiological environment and energy metabolism of NPCs, there is reason to consider that autophagy in NPCs under hypoxia should be different from that of other types of cells. Autophagy has a dual effect on the survival of NPCs in serum-free culture conditions; proper autophagy activity of cells promotes NPC survival, while excessive autophagy promotes NPC death (45). Hypoxia enhances NPC survival under serum-free culture conditions via the downregulation of excessive autophagy activity, including limiting the generation of reactive oxygen species and promoting the inactivation of the AMPK/mTOR signalling pathway; this process may be controlled by HIF-1 $\alpha$ (45). On the other hand, contrary to previous investigations, Choi et al (169) confirmed that hypoxia enhances the non-classical autophagy of NPCs, and this process is not related to the mTOR and HIF-1 $\alpha$ signalling pathways. This process does not affect the glycolytic metabolism of NPCs (169), which suggests that autophagy in NPCs may have other effects besides its classical degradation and recapture function. Therefore, further studies are needed to determine the physiological role of autophagy in NPCs and how it contributes to alleviate IDD.

Apoptosis. The biological activity of NPCs is indispensable for maintaining the stability and function of the IVD. Accumulating evidence suggests that excessive apoptosis and senescence of NPCs can lead to ECM degeneration in the $\mathrm{NP}$, and it has been considered that it could be a therapeutic target in IDD $(170,171)$. Gruber et al (171) studied postoperative specimens and found that the apoptosis of a large number of cells was detected in IVD, while active cells synthesize degraded ECM components, impeding cell growth and communication by altering the environment surrounding NP. It is becoming increasingly evident that HIF-1 $\alpha$ is widely involved in the regulation of NPC survival. The positive correlation between the expression of HIF-1 $\alpha$ and NPC apoptosis was analyzed in patients with disc herniation (43). In this review it is hypothesized that the survival state of NPCs is related to the severity of hypoxia under hypoxic environments; there is an oxygen threshold beyond which the expression of pro-apoptotic proteins and VEGF is reinforced. Moritz et al (59) and Liu et al (35) also found that HIF-1 $\alpha$ has a dual function in vivo, and the alternative function of HIF-1 $\alpha$ depends on the oxygen tension (Figs. 3 and 4). Some pro-apoptotic proteins, such as BNIP3, are downstream target genes of HIF-1 $\alpha$ (166). BNIP3 can induce the apoptosis of NPCs via the mitochondrial pathway, and it is also involved in inducing mitochondrial autophagy, promoting cells to adapt to various metabolic reactions and exerting anti-apoptotic benefits (155). Forkhead box O3 (FOXO3a), which regulates resistance to various stresses and promotes cell survival, decreases the expression of BNIP3 by promoting the activity of the transcription cofactor cbp/P33 interacting transactivator 2 to inhibit apoptosis (172). In addition, inflammatory cytokines, decreased energy metabolism, ECM imbalance and angiogenesis, all promote apoptosis in varying degrees.

Increasingly, investigations have tended to support that HIF-1 $\alpha$ enhances the NPCs adaptability to hypoxia and consolidates NPC survival under hypoxic conditions. The HIF-1 $\alpha /$ VEGF pathway plays a vital role in maintaining the ECM balance of NPCs and promoting NPC survival (42). The function of VEGF is also restricted to the VEGF/membrane bound VEGF receptor-1 axis (173). The NPCs derived from progenitor cells were vulnerable to apoptosis in hypoxic conditions due to their inability to induce the expression of HIF-1 $\alpha$ (174). After proteoglycans were added, the activation of HIF-1 $\alpha$ was subsequently consolidated, and the susceptibility of progenitor cells to apoptosis induced by hypoxia was reduced (174). HIF-1 $\alpha$ inhibits Fas ligand-mediated apoptosis by reinforcing the activation of the galectin-3 promoter (175). In addition, HIF-1 $\alpha$ can enhance the expression of carbonic anhydrase (CA)-12 to increase the synthesis of the ECM of NP (4). HIF-1 $\alpha$ is also involved in CA9/12-mediated bicarbonate cycling to maintain the $\mathrm{pH}$ stability of NP (176).

Dystrophic calcification. Although IVD is enriched in collagen fibrin and moisture, abnormal pyknotic substances are not deposited within NP under physiological conditions (48). The dysregulation of inorganic phosphate metabolism plays a key role in CEC (177), and its expression level can be used to assess the degree of CEC (178). The progressive ankylosis protein homolog gene (ANK) is a phosphate transporter that can prevent mineralization by regulating the transport of inorganic phosphates $(48,179)$. ANK is involved in the local control of mineralization in bone, cartilage and the calcified tissue area of growth plates $(179,180)$. Malnutrition mineralization caused by abnormal expression of ANK can lead to the occurrence of chronic diseases such as osteoarthritis $(179,180)$ and IDD $(48,181)$. Sohn et al (182) found that ANK is mainly expressed on the surface and hypertrophic areas of joints and cartilage, which indicates that the expression of ANK is oxygen-dependent. Zaka et al (183) demonstrated that the expression of $A N K$ in growth plate chondrocytes depends on the regulation of HIF-1 $\alpha$. However, Skubutyte et al (48) found that ANK was highly expressed in calcified areas of cartilage endplates enriched in blood supply and in NP tissues lacking blood supply, suggesting that there is an intrinsic difference in the regulation of ANK between the NP and the growth plate. A previous study found that HIF-1 $\alpha$ or HIF- $2 \alpha$ directly negatively regulate the expression of ANK, indicating that the expression of HIF- $1 \alpha$ or HIF- $2 \alpha$ can 
maintain the physiological level of ANK under physiological conditions, thereby preventing the occurrence of dystrophic mineralization and promoting NPCs to adapt to the hypoxic environment (48). Interestingly, although the expression of HIF proteins is not related to oxygen tension, silencing HIF further increases the expression of ANK during hypoxia, indicating that hypoxia can also regulate can regulate TGF- $\beta$ expression to modulate ANK promoter activity in a HIF-independent manner (Fig. 3) (48).

Transplantation. Cell transplantation repair or even reconstruction of degenerate IVD could be used to treat IDD. Wang et al (184) injected NPCs into an established IDD mouse model and found that transplanted NPCs can counteract apoptosis, increase the expression of ECM and promote NPC migration to the damaged area, thereby alleviating IDD. Yang et al $(46,47)$ found that the isolation, expansion and culture of human degenerate NPCs can successfully preserve the regenerative capacity of NPCs during hypoxia. The expression of HIF-1 $\alpha$ is enhanced under hypoxia, which can promote cell proliferation and maintain the functional phenotype of NPCs. Therefore, it is necessary to isolate and amplify NPCs during hypoxia to pave the way for post-cultivation or cell transplantation. The energy metabolism of transplanted NPCs relies on the HIF-1 $\alpha$-GLUT1 pathway (Fig. 3) (150).

\section{HIF-1 $\alpha$ development trends}

Spontaneous absorption of prolapsed IVD tissues. An increasing number of studies have reported herniated disc tissue retraction or even disappearance in patients with lumbar disc herniation previously diagnosed by MRI (14-16). Macrophages, angiogenesis, MMPs and inflammatory cytokines play an important role in this process $(104,107,112,113)$. HIF-1 $\alpha$ mediates macrophage infiltration, and their role in acute inflammation response, via the regulation of ATP production (63). HIF-1 $\alpha$ also enhances the phagocytic activity of M1 macrophages and the expression of pro-inflammatory cytokines and VEGF $(8,130,185)$. Due to the network regulatory relationships among HIF- $1 \alpha$ and angiogenesis, MMPs and inflammatory cytokines (Fig. 3), in this review it is hypothesized that HIF-1 $\alpha$ may be involved in regulating the spontaneous absorption of prolapsed IVD tissue. The possible mechanisms need further research.

HIF-1 $\alpha$ may be a common relay station of non-coding RNAs. Numerous studies have reported that non-coding RNAs, including miRNAs, long non-coding (lnc)RNAs and newly discovered circular (circ)RNAs, play an important role in the occurrence and progression of IDD. More importantly, numerous non-coding RNAs are associated with HIF-1 $\alpha(35,53,108,186-191)$, as shown in Table I. Liu et al (35) confirmed that miR-335 can directly regulate the expression of HIF-1 $\alpha$, and found that HIF- $1 \alpha$ has a dual role in the regulation of cerebral ischaemia. Wang et al (53) found that lncRNA-RP11-296A18.3 enhances the expression of HIF-1 $\alpha$ by sequestering miR-138, which in turn promotes human NPC proliferation and ECM synthesis. Serocki et al (188) reviewed the miRNAs and lncRNAs that can regulate the HIF- $1 \alpha$ switch and found that they are mainly involved in process of cell proliferation, migration, angiogenesis and hypoxia. lncRNAs regulate HIF-1 $\alpha$ directly (188) and can indirectly regulate HIF-1 $\alpha$ expression by sequestering miRNAs $(53,188,189)$. In the present review, the focus is mainly on the circRNAs that are associated with HIF-1 $\alpha$ (180-191). Liang et al (186) found that the expression of circDENND4C was enhanced in breast cancer cells under hypoxia, and reduced after HIF-1 $\alpha$ knockdown. Thus, indicating that HIF-1 $\alpha$ mediates cell metabolism via regulating the expression of circRNA. Interestingly, circRNA mediates HIF-1 $\alpha$ metastasis to reverse its biofunction (188). Du et al (187) reported that circ-Foxo3 was enriched in the cytoplasm and absorbs HIF-1 $\alpha$, which was originally highly expressed in the nucleus and translocated into the cytoplasm to promote cell senescence. Dang et al (190) found that circ_0010729 can sequester miR-186 to relieve the inhibitory effect of miR-186 on HIF-1 $\alpha$, thereby promoting vascular endothelial cell proliferation and migration, and inhibiting apoptosis. Liu et al (191) first studied the expression profile of circRNAs in osteosarcoma and found that circRNA_103801 expression was markedly upregulated. Functional enrichment analysis showed that it could play a role in cancer signalling pathways, such as HIF-1 $\alpha$, VEGF and angiogenesis (191). circRNAs have an effect on mitigating IDD (Table II) $(125,126,192)$. Cheng et al (125) demonstrated that circVMA21 reduces inflammatory cytokine-induced NPC death and the expression of MMPs and ADAMTSs, as well as increasing the synthesis of COL2 and ACAN in in vitro experiments. Subsequently, the results of in vivo experiments were in accordance with the in vitro experiments, suggesting that the circVMA21/miR-200c/XIAP axis plays a crucial role in mitigating IDD (126). Guo et al (192) further demonstrated that the circ-GRB10/miR-328-5p/erb-B2 receptor tyrosine kinase 2 axis can also regulate NPC apoptosis. Wang et al (126) reported that TNF- $\alpha$ enhances the expression of circ-4099, which promotes the synthesis of SOX9 via the sequestering of miR-616-5p. However, these three experiments do have similar limitations; the key genes researched do not necessarily play a major role in IDD. As the purpose of studying the genes involved in IDD is so that the results can go on to be applied in the clinic, the key genes should be selected for study. In this review, it is questioned whether circRNAs participate in the regulation of IDD via modulating the HIF-1 $\alpha$ switch. In summary, it is further speculated that HIF-1 $\alpha$ may be a common relay site for non-coding RNAs regulating IDD. It is necessary to further investigate the role of the circRNA-miRNA-HIF-1 $\alpha$-MMP-ECM signalling pathway in regulating the progression of IDD.

Clinical conversion. Increasingly, patients with LBP in the clinic are shown to have protrusive or degenerative IVD via MRI imaging (14-16). Pfirrmann et al (193) mainly used MRI to classify the grade of the severity of IDD, without considering the microenvironmental factors of IVD. The IVD microenvironment has already become dysregulated before MRI shows positive results, such as protrusion or degeneration of the IVD $(25,40,77)$. Thus, even if a negative result is detected by MRI, it cannot be ruled out that the IVD microenvironment has already deteriorated. Therefore, compared with Pfirrmann's 'external grading', the 'internal grading' of the degree of microenvironmental disturbance within IVD can 
easily be neglected before this type of patient has a positive result. Consequently, it is crucial to determine the 'internal grading' of the severity of IDD as soon as possible and to intervene early to block the vicious cycle of degeneration. This also opens up alternative avenues for patients who have results contradictory to MRI imaging. In view of the fact that IVD has no vascular structures $(19,22)$, the diagnosis of the 'internal grading' of IDD relies on puncture only. Ultrasound-guided puncture has the advantages of accurate positioning, convenient operation, economy, and both diagnosis and treatment, as well as having clinical applicability (194). HIF-1 $\alpha$, as the most important molecule regulating the degeneration of human IVD (30), is a common relay station for the regulation of a number of non-coding RNA molecules (35,53,108,186-191). The various mechanisms affecting IDD interact with each other and ultimately regulate ECM metabolism (25,77-79). Therefore, the dysregulation of ECM metabolism is the most important mechanism affecting IDD. Water loss within the NP is an important feature of IDD $(24,40,77)$. Although MMPs (49-52), inflammatory factors $(8,103,125)$ and various related proteins $(90,114,120,155)$ also play an important role in IDD, they are indirectly reflected by HIF-1 $\alpha$ and ECM and may not be included in the evaluation index. Therefore, HIF-1 $\alpha$, ECM (the content and distribution of ACAN and COL2 and other collagens) and $\mathrm{H}_{2} \mathrm{O}$ can be used as the evaluation criteria for the pathological diagnosis of the 'internal grading' of the degree of microenvironmental disorder in IVD. However, the challenges faced by this method should be noted. This includes how to puncture for the biopsy and its feasibility (why patients should take an invasive examination and where is the value). Therefore, further research is needed to demonstrate that early precaution and intervention can avoid advanced surgery. Additionally, another challenge concerns the determination of reference values of various evaluation indicators. circRNAs are tissue-specific and can serve as markers of disease (195) so greater challenges include further screening of circRNAs with markers that indirectly reflect the expression of HIF-1 $\alpha$ and ECM, and then diagnose the degree of IDD through the drawing of blood.

\section{Conclusions}

In summary, this review put forward three invaluable and strongly indispensable research questions. Firstly, HIF- $1 \alpha$ is a double-edged sword in modulating the occurrence and progression of IDD, which is related to the oxygen tension of the IVD microenvironment. The oxygen tension is gradually decreased with the progression of the vicious cycle. The HIF-dependent pathways play a friendly role during moderate hypoxia, while playing a foe role in severe hypoxia. Is it possible to alter the oxygen tension indirectly, in order to control the expression of HIF-1 $\alpha$ and to treat IDD? Secondly, HIF-1 $\alpha$ has the ability to regulate all other mechanisms involved in IDD, and it may also be a common relay station for a number of non-coding RNAs that regulate the progression of IDD. Does the circRNA-miRNA-HIF-1 $\alpha$-MMP2-ECM signalling pathway play a crucial role in regulating the progression of IDD? Thirdly, puncturing the IVD to obtain NP tissue for biopsy, guided by B-ultrasound, could be a novel and vital method for early diagnosis and treatment in cases where the patient is displaying symptoms but MRI is showing a negative result. So, how feasible is this diagnosis method? Why undergo an invasive examination, and where is the value? Can levels of HIF-1 $\alpha$, ACAN, COL2, VEGF and $\mathrm{H}_{2} \mathrm{O}$ be used as evaluation criteria for the pathological diagnosis of the 'internal grading' of the degree of IVD microenvironmental dysregulation? Further research is needed to answer these questions in order to aid the clinical diagnosis and treatment of IDD.

\section{Acknowledgements}

The authors would like to thank Professor Shiqing Feng, for his guidance on article design and critically review the article.

\section{Funding}

This study was supported by the State Key Program of the National Natural Science Foundation of China (grant no. 81330042), the Special Program for Sino-Russian Joint Research Sponsored by the Ministry of Science and Technology, China (grant no. 2014DFR31210), and the International Cooperation Program of the National Natural Science Foundation of China (grant no. 81620108018).

\section{Availability of data and materials}

Not applicable.

\section{Authors' contributions}

YL, SL and DP contributed to the concept and the design of the review. YL and DP wrote the manuscript. SL, GN and XX helped draft the manuscript and drew the figures. BX provided significant suggestions for the study. HZ, BZ, SZ searched the literature and collated important reference information. SF critically reviewed the manuscript. All authors read and approved the final manuscript.

\section{Ethics approval and consent to participate}

Not applicable.

\section{Patient consent for publication}

Not applicable.

\section{Competing interests}

The authors declare that they have no competing interests.

\section{References}

1. Deyo RA and Tsui-Wu YJ: Descriptive epidemiology of low-back pain and its related medical care in the United States. Spine (Phila Pa 1976) 12: 264-268, 1987.

2. Andersson GB: Epidemiological features of chronic low-back pain. Lancet 354: 581-585, 1999.

3. Vos T, Flaxman AD, Naghavi M, Lozano R, Michaud C, Ezzati M, Shibuya K, Salomon JA, Abdalla S, Aboyans V, et al: Years lived with disability (YLDs) for 1160 sequelae of 289 diseases and injuries 1990-2010: A systematic analysis for the Global Burden of Disease Study 2010. Lancet 380: 2163-2196, 2012. 
4. Chen S, Fang XQ, Wang Q, Wang SW, Wang SW, Hu ZJ,Zhou ZJ, Xu WB, Wang JY, Qin A and Fan SW: PHD/HIF-1 upregulates CA12 to protect against degenerative disc disease: A human sample, in vitro and ex vivo study. Lab Invest 96: 561-569, 2016.

5. LuomaK, RiihimäkiH,Luukkonen R, Raininko R, Viikari-JunturaE and Lamminen A: Low back pain in relation to lumbar disc degeneration. Spine (Phila Pa 1976) 25: 487-492, 2000

6. Samartzis D, Karppinen J, Mok F, Fong DY, Luk KD and Cheung KM: A population-based study of juvenile disc degeneration and its association with overweight and obesity, low back pain, and diminished functional status. J Bone Joint Surg Am 93: 662-670, 2011.

7. Verrills P, Nowesenitz G and Barnard A: Prevalence and characteristics of discogenic pain in tertiary practice: 223 consecutive cases utilizing lumbar discography. Pain Med 16: 1490-1499, 2015

8. Risbud MV and Shapiro IM: Role of cytokines in intervertebral disc degeneration: Pain and disc content. Nat Rev Rheumatol 10 44-56, 2014

9. Bijkerk C, Houwing-Duistermaat JJ, Valkenburg HA, Meulenbelt I, Hofman A, Breedveld FC, Pols HA, van Duijn CM and Slagboom PE: Heritabilities of radiologic osteoarthritis in peripheral joints and of disc degeneration of the spine. Arthritis Rheum 42: 1729-1735, 1999.

10. Sambrook PN, MacGregor AJ and Spector TD: Genetic influences on cervical and lumbar disc degeneration: A magnetic resonance imaging study in twins. Arthritis Rheum 42: 366-372, 1999.

11. Battié MC, Videman T, Gibbons LE, Fisher LD, Manninen H and Gill K: 1995 Volvo award in clinical sciences: Determinants of lumbar disc degeneration. A study relating lifetime exposures and magnetic resonance imaging findings in identical twins. Spine (Phila Pa 1976) 20: 2601-2612, 1995.

12. van den Eerenbeemt KD, Ostelo RW, van Royen BJ, Peul WC and van Tulder MW: Total disc replacement surgery for symptomatic degenerative lumbar disc disease: A systematic review of the literature. Eur Spine J 19: 1262-1280, 2010.

13. Jacobs WC, van der Gaag NA, Kruyt MC, Tuschel A, de Kleuver M, Peul WC, Verbout AJ and Oner FC: Total disc replacement for chronic discogenic low back pain: A Cochrane review. Spine (Phila Pa 1976) 38: 24-36, 2013.

14. Nozawa S, Nozawa A, Kojima H and Shimizu K: Spontaneous disappearance of lumbar disk herniation within 3 months. Orthopedics 32: 852, 2009

15. Ryu SJ and Kim IS: Spontaneous regression of a large lumbar disc extrusion. J Korean Neurosurg Soc 48: 285-287, 2010.

16. Gao S, Geng X and Fang Q: Spontaneous disappearance of large lumbar disk herniation. JAMA Neurol 75: 123-124, 2018.

17. Humzah MD and Soames RW: Human intervertebral disc: Structure and function. Anat Rec 220: 337-356, 1988.

18. Nerlich AG, Boos N, Wiest I and Aebi M: Immunolocalization of major interstitial collagen types in human lumbar intervertebral discs of various ages. Virchows Arch 432: 67-76, 1988.

19. Ogata K and Whiteside LA: 1980 Volvo award winner in basic science. Nutritional pathways of the intervertebral disc. An experimental study using hydrogen washout technique. Spine (Phila Pa 1976) 6: 211-216, 1981.

20. Gruber HE, Ashraf N, Kilburn J, Williams C, Norton HJ, Gordon BE and Hanley EN Jr: Vertebral endplate architecture and vascularization: Application of micro-computerized tomography, a vascular tracer, and immunocy tochemistry in analyses of disc degeneration in the aging sand rat. Spine (Phila $\mathrm{Pa}$ 1976) 30 2593-2600, 2005.

21. Fujita N, Markova D, Anderson DG, Chiba K, Toyama Y, Shapiro IM and Risbud MV: Expression of prolyl hydroxylases (PHDs) is selectively controlled by HIF-1 and HIF-2 proteins in nucleus pulposus cells of the intervertebral disc: Distinct roles of PHD2 and PHD3 proteins in controlling HIF-1 $\alpha$ activity in hypoxia. J Biol Chem 287: 16975-16986, 2012.

22. Kim KW, Lim TH, Kim JG, Jeong ST, Masuda K and An HS: The origin of chondrocytes in the nucleus pulposus and histologic findings associated with the transition of a notochordal nucleus pulposus to a fibrocartilaginous nucleus pulposus in intact rabbit intervertebral discs. Spine (Phila Pa 1976) 28: 982-990, 2003.

23. Urban JP, Smith S and Fairbank JC: Nutrition of the intervertebral disc. Spine (Phila Pa 1976) 29: 2700-2709, 2004.

24. Guiot BH and Fessler RG: Molecular biology of degenerative disc disease. Neurosurgery 47: 1034-1040, 2000

25. Feng G, Jin X, Hu J, Ma H, Gupte MJ, Liu H and Ma PX: Effects of hypoxias and scaffold architecture on rabbit mesenchymal stem cell differentiation towards a nucleus pulposus-like phenotype. Biomaterials 32: 8182-8189, 2011.
26. Sakai D and Grand S: Advancing the cellular and molecular therapy for intervertebral disc disease. Adv Drug Deliv Rev 84: 159-171, 2015.

27. Risbud MV, Schipani E and Shapiro IM: Hypoxic regulation of nucleus pulposus cell survival: From niche to notch. Am J Pathol 176: 1577-1583, 2010

28. Feng G, Li L, Liu H, Song Y, Huang F, Tu C, Shen B, Gong Q, Li T, Liu L, et al: Hypoxia differentially regulates human nucleus pulposus and annulus fibrosus cell extracellular matrix production in 3D scaffolds. Osteoarthritis Cartilage 21: 582-588, 2013.

29. Feng G, Li L, Hong Y, Liu H, Song Y, Pei F, Ma PX, Gong Q and Gupte MJ: Hypoxia promotes nucleus pulposus phenotype in 3D scaffolds in vitro and in vivo: Laboratory investigation. J Neurosurg Spine 21: 303-309, 2014.

30. Semenza GL: Life with oxygen. Science 318: 62-64, 2007.

31. Richardson SM, Knowles R, Tyler J, Mobasheri A and Hoyland JA: Expression of glucose transporters GLUT-1, GLUT-3, GLUT-9 and HIF-1alpha in normal and degenerate human intervertebral disc. Histochem Cell Biol 129: 503-511, 2008.

32. Benita Y, Kikuchi H, Smith AD, Zhang MQ, Chung DC and Xavier RJ: An integrative genomics approach identifies Hypoxia Inducible Factor-1 (HIF-1)-target genes that form the core response to hypoxia. Nucleic Acids Res 37: 4587-4602, 2009.

33. Semenza GL: Hypoxia-inducible factor 1: Control of oxygen homeostasis in health and disease. Pediatr Res 49: 614-617, 2001.

34. Sharp FR and Bernaudin M: HIF1 and oxygen sensing in the brain. Nat Rev Neurosci 5: 437-448, 2004.

35. Liu FJ, Kaur P, Karolina DS, Sepramaniam S, Armugam A, Wong PT and Jeyaseelan K: MiR-335 regulates hif- $1 \alpha$ to reduce cell death in both mouse cell line and rat ischemic models. PLoS One 10: e0128432, 2015.

36. Eales KL, Hollinshead KE and Tennant DA: Hypoxia and metabolic adaptation of cancer cells. Oncogenesis 5: e190, 2016.

37. Giatromanolaki A, Sivridis E, Maltezos E, Athanassou N, Papazoglou D, Gatter KC, Harris AL and Koukourakis MI: Upregulated hypoxia inducible factor-1alpha and -2alpha pathway in rheumatoid arthritis and osteoarthritis. Arthritis Res Ther 5: R193-R201, 2003.

38. Yang S, Kim J, Ryu JH, Oh H, Chun CH, Kim BJ, Min BH and Chun JS: Hypoxia-inducible factor-2alpha is a catabolic regulator of osteoarthritic cartilage destruction. Nat Med 16: 687-693, 2010.

39. Konisti S, Kiriakidis S and Paleolog EM: Hypoxia-a key regulator of angiogenesis and inflammation in rheumatoid arthritis. Nat Rev Rheumatol 8: 153-162, 2012.

40. Vergroesen PP, Kingma I, Emanuel KS, Hoogendoorn RJ, Welting TJ, van Royen BJ, van Dieën JH and Smit TH: Mechanics and biology in intervertebral disc degeneration: A vicious circle. Osteoarthritis Cartilage 23: 1057-1070, 2015

41. Kwon WK, Moon HJ, Kwon TH, Park YK and Kim JH: The role of hypoxia in angiogenesis and extracellular matrix regulation of intervertebral disc cells during inflammatory reactions. Neurosurgery 81: 867-875, 2017.

42. Wu WJ, Zhang XK, Zheng XF, Yang YH, Jiang SD and Jiang LS: SHH-dependent knockout of HIF-1 alpha accelerates the degenerative process in mouse intervertebral disc. Int J Immunopathol Pharmacol 26: 601-609, 2013.

43. Ha KY, Koh I, Kirpalani PA, Kim YY, Cho YK, Khang GS and Han CW: The expression of hypoxia inducible factor-lalpha and apoptosis in herniated discs. Spine (Phila Pa 1976) 31: 1309-1313, 2006.

44. Hu CJ, Wang LY, Chodosh LA, Keith B and Simon MC: Differential roles of hypoxia-inducible factor 1alpha (HIF-1alpha) and HIF-2alpha in hypoxic gene regulation. Mol Cell Biol 23: 9361-9374, 2003

45. Chen JW, Ni BB, Zheng XF, Li B, Jiang SD and Jiang LS: Hypoxia facilitates the survival of nucleus pulposus cells in serum deprivation by down-regulating excessive autophagy through restricting ROS generation. Int J Biochem Cell Biol 59: $1-10,2015$.

46. Yang SH, Hu MH, Sun YH and Lin FH: Differential phenotypic behaviors of human degenerative nucleus pulposus cells under normoxic and hypoxic conditions: Influence of oxygen concentration during isolation, expansion, and cultivation. Spine J 13: $1590-1596,2013$

47. Yang SH, Hu MH, Lo WY, Sun YH, Wu CC and Yang KC: The influence of oxygen concentration on the extracellular matrix production of human nucleus pulposus cells during isolation-expansion process. J Biomed Mater Res A 105: 1575-1582, 2017. 
48. Skubutyte R, Markova D, Freeman TA, Anderson DG, Dion AS, Williams CJ, Shapiro IM and Risbud MV: Hypoxia-inducible factor regulation of ANK expression in nucleus pulposus cells: Possible implications in controlling dystrophic mineralization in the intervertebral disc. Arthritis Rheum 62: 2707-2715, 2010

49. Jing SW, Wang YD, Kuroda M, Su JW, Sun GG, Liu Q, Cheng YJ and Yang CR: HIF-1 $\alpha$ contributes to hypoxia-induced invasion and metastasis of esophageal carcinoma via inhibiting E-cadherin and promoting MMP-2 expression. Acta Med Okayama 66: 399-407, 2012.

50. Rodrigues $\mathrm{M}$, Xin X, Jee K, Babapoor-Farrokhran S, Kashiwabuchi F, Ma T, Bhutto I, Hassan SJ, Daoud Y, Baranano D, et al: VEGF secreted by hypoxic Müller cells induces MMP-2 expression and activity in endothelial cells to promote retinal neovascularization in proliferative diabetic retinopathy. Diabetes 62: 3863-3873, 2013.

51. Tsai SH, Huang PH, Hsu YJ, Peng YJ, Lee CH, Wang JC, Chen JW and Lin SJ: Inhibition of hypoxia inducible factor-1 $\alpha$ attenuates abdominal aortic aneurysm progression through the down-regulation of matrix metalloproteinases. Sci Rep 6: 28612, 2016.

52. Wu WP, Jiang JM, Qu DB, Wei QZ and Jiang H: Expression of hypoxia-inducible factor-1alpha and matrix metalloproteinase-2 in degenerative lumbar intervertebral disc. Nan Fang Yi Ke Da Xue Xue Bao 30: 1152-1155, 2010 (In Chinese).

53. Wang $X$, Lv G, Li J, Wang B, Zhang $Q$ and Lu C: LncRNA-RP11-296A18.3/miR-138/HIF1A pathway regulates the proliferation ECM synthesis of human nucleus pulposus cells (HNPCs). J Cell Biochem 118: 4862-4871, 2017.

54. Huang LE, Gu J, Schau M and Bunn HF: Regulation of hypoxia-inducible factor 1alpha is mediated by an $\mathrm{O}_{2}$-dependent degradation domain via the ubiquitin-proteasome pathway. Proc Natl Acad Sci USA 95: 7987-7992, 1998.

55. Lee JW, Bae SH Jeong JW, Kim SH and Kim KW: Hypoxia-inducible factor (HIF-1)alpha: Its protein stability and biological functions. Exp Mol Med 36: 1-12, 2004.

56. Wenger RH: Cellular adaptation to hypoxia: O2-sensing protein hydroxylases, hypoxia-inducible transcription factors, and O2-regulated gene expression. FASEB J 16: 1151-1162, 2002.

57. Makino Y, Kanopka A, Wilson WJ, Tanaka $\mathrm{H}$ and Poellinger L: Inhibitory PAS domain protein (IPAS) is a hypoxia-inducible splicing variant of the hypoxia-inducible factor-3alpha locus. J Biol Chem 277: 32405-32408, 2002

58. Pasanen A, Heikkilä M, Rautavuoma K, Hirsilä M, Kivirikko KI and Myllyharju J: Hypoxia-inducible factor (HIF)-3alpha is subject to extensive alternative splicing in human tissues and cancer cells and is regulated by HIF-1 but not HIF-2. Int J Biochem Cell Biol 42: 1189-1200, 2010

59. Moritz W, Meier F, Stroka DM, Giuliani M, Kugelmeier P, Nett PC, Lehmann R, Candinas D, Gassmann M and Weber M: Apoptosis in hypoxic human pancreatic islets correlates with HIF-1alpha expression. FASEB J 16: 745-747, 2002.

60. Wenger RH and Gassmann M: Oxygen(es) and the hypoxia-inducible factor-1. Biol Chem 378: 609-616, 1997.

61. Ema M, Taya S, Yokotani N, Sogawa K, Matsuda Y and Fujii-Kuriyama Y: A novel bHLH-PAS factor with close sequence similarity to hypoxia-inducible factor 1alpha regulates the VEGF expression and is potentially involved in lung and vascular development. Proc Natl Acad Sci USA 94: 4273-4278, 1997.

62. Tian H, McKnight SL and Russell DW: Endothelial PAS domain protein 1 (EPAS1), a transcription factor selectively expressed in endothelial cells. Genes Dev 11: 72-82, 1997.

63. Imtiyaz HZ, Williams EP, Hickey MM, Patel SA, Durham AC Yuan LJ, Hammond R, Gimotty PA, Keith B and Simon MC: Hypoxia-inducible factor 2alpha regulates macrophage function in mouse models of acute and tumor inflammation. J Clin Invest 120: 2699-2714, 2010.

64. Madsen CD, Pedersen JT, Venning FA, Singh LB, Moeendarbary E, Charras G, Cox TR, Sahai E and Erler JT: Hypoxia and loss of PHD2 inactivate stromal fibroblasts to decrease tumour stiffness and metastasis. EMBO Rep 16 : 1394-1408, 2015

65. Fujita N, Chiba K, Shapiro IM and Risbud MV: HIF-1 $\alpha$ and HIF-2 $\alpha$ degradation is differentially regulated in nucleus pulposus cells of the intervertebral disc. J Bone Miner Res 27: 401-412, 2012

66. Raval RR, Lau KW, Tran MG, Sowter HM, Mandriota SJ, Li JL, Pugh CW, Maxwell PH, Harris AL and Ratcliffe PJ: Contrasting properties of hypoxia-inducible factor 1 (HIF-1) and HIF-2 in von Hippel-Lindau-associated renal cell carcinoma. Mol Cell Biol 25: 5675-5686, 2005
67. Eyre DR, Benya P, Buckwalter JA, Caterson B, Heinegard D, Oegema T, Pearce R, Pope M and Urban J (eds): Basic Sciences Perspectives: Part B-Intervertebral Discs. Park Ridge, American Academy of Orthopaedic Surgeons, pp147-207, 1989.

68. Shao J, Yu M, Jiang L, Wei F, Wu F, Liu Z and Liu X: Differences in calcification and osteogenic potential of herniated discs according to the severity of degeneration based on Pfirrmann grade: A cross-sectional study. BMC Musculoskelet Disord 17: 191, 2016.

69. Grant MP, Epure LM, Bokhari R, Roughley P, Antoniou J and Mwale F: Human cartilaginous endplate degeneration is induced by calcium and the extracellular calcium-sensing receptor in the intervertebral disc. Eur Cell Mater 32: 137-151, 2016.

70. Karamouzian S, Eskandary H, Faramarzee M, Saba M, Safizade H, Ghadipasha M, Malekpoor AR and Ohadi A: Frequency of lumbar intervertebral disc calcification and angiogenesis, and their correlation with clinical, surgical, and magnetic resonance imaging findings. Spine (Phila Pa 1976) 35: 881-886, 2010.

71. Adams MA and Roughley PJ: What is intervertebral disc degeneration, and what causes it? Spine (Phila Pa 1976) 31: 2151-2161, 2006.

72. Eyre DR and Muir H: Quantitative analysis of types I and II collagens in human intervertebral discs at various ages. Biochim Biophys Acta 492: 29-42, 1977.

73. Roughley P, Martens D, Rantakokko J, Alini M, Mwale F and Antoniou J: The involvement of aggrecan polymorphism in degeneration of human intervertebral disc and articular cartilage. Eur Cell Mater 11: 1-7, 2006.

74. Hu B, Xu C, Tian Y, Shi C, Zhang Y, Deng L, Zhou H, Cao P, Chen $\mathrm{H}$ and Yuan W: Inflammatory microRNA-194 and -515 attenuate the biosynthesis of chondroitin sulfate during human intervertebral disc degeneration. Oncotarget 8: 49303-49317, 2017.

75. Poole AR: Biologic markers and disc degeneration. J Bone Joint Surg Am 88 (Suppl 2): S72-S75, 2006.

76. Duance VC, Crean JK, Sims TJ, Avery N, Smith S, Menage J, Eisenstein SM and Roberts S: Changes in collagen cross-linking in degenerative disc disease and scoliosis. Spine (Phila Pa 1976) 23: 2545-2551, 1998.

77. Vo NV, Hartman RA, Patil PR, Risbud MV, Kletsas D, Iatridis JC, Hoyland JA, Le Maitre CL, Sowa GA and Kang JD: Molecular mechanisms of biological aging in intervertebral discs. J Orthop Res 34: 1289-1306, 2016.

78. Peck SH, McKee KK, Tobias JW, Malhotra NR, Harfe BD and Smith LJ: Whole transcriptome analysis of notochord-derived cells during embryonic formation of the nucleus pulposus. Sci Rep 7: 10504, 2017.

79. Freemont AJ: The cellular pathobiology of the degenerate intervertebral disc and discogenic back pain. Rheumatology (Oxford) 48: 5-10, 2009.

80. Liu Z, Li C, Meng X, Bai Y, Qi J, Wang J, Zhou Q, Zhang W and Zhang $X$ : Hypoxia-inducible factor-l $\alpha$ mediates aggrecan and collagen $\Pi$ expression via NOTCH1 signaling in nucleus pulposus cells during intervertebral disc degeneration. Biochem Biophys Res Commun 488: 554-561, 2017.

81. Chen D, Li M, Luo J and Gu W: Direct interactions between HIF-1 alpha and Mdm2 modulate p53 function. J Biol Chem 278: 13595-13598, 2003.

82. Aro E, Khatri R, Gerard-O'Riley R, Mangiavini L, Myllyharju J and Schipani E: Hypoxia-inducible factor-1 (HIF-1) but not HIF-2 is essential for hypoxic induction of collagen prolyl 4-hydroxylases in primary newborn mouse epiphyseal growth plate chondrocytes. J Biol Chem 287: 37134-37144, 2012.

83. Meretoja VV, Dahlin RL, Wright S, Kasper FK and Mikos AG: The effect of hypoxia on the chondrogenic differentiation of co-cultured articular chondrocytes and mesenchymal stem cells in scaffolds. Biomaterials 34: 4266-4273, 2013.

84. Gilkes DM, Bajpai S, Chaturvedi P, Wirtz D and Semenza GL: Hypoxia-inducible factor 1 (HIF-1) promotes extracellular matrix remodeling under hypoxic conditions by inducing P4HA1, P4HA2, and PLOD2 expression in fibroblasts. J Biol Chem 288: 10819-10829, 2014

85. Mwale F, Ciobanu I, Giannitsios D, Roughley P, Steffen T and Antoniou J: Effect of oxygen levels on proteoglycan synthesis by intervertebral disc cells. Spine (Phila Pa 1976) 36: E131-E138, 2011.

86. Pei M, Shoukry M, Li J, Daffner SD, France JC and Emery SE: Modulation of in vitro microenvironment facilitates synovium derived stem cell-based nucleus pulposus tissue regeneration. Spine (Phila Pa 1976) 37: 1538-1547, 2012. 
87. Ishihara $\mathrm{H}$ and Urban JP: Effects of low oxygen concentration and metabolic inhibitors on proteoglycan and protein synthesis rates in the intervertebral disc. J Orthop Res 17: 829-835, 1999.

88. Cigognini D, Gaspar D, Kumar P, Satyam A, Alagesan S Sanz-Nogués C, Griffin M, O'Brien T, Pandit A and Zeugolis DI: Macromolecular crowding meets oxygen tension in human mesenchymal stem cell culture-A step closer to physiologically relevant in vitro organogenesis. Sci Rep 6: 30746, 2016.

89. Obradovic B, Carrier RL, Vunjak-Novakovic G and Freed LE: Gas exchange is essential for bioreactor cultivation of tissue engineered cartilage. Biotechnol Bioeng 63: 197-205, 1999.

90. Folkman J: Angiogenesis in cancer, vascular, rheumatoid and other disease. Nat Med 1: 27-31, 1995.

91. Senger DR, Van de Water L, Brown LF, Nagy JA, Yeo KT, Yeo TK, Berse B, Jackman RW, Dvorak AM and Dvorak HF: Vascular permeability factor (VPF, VEGF) in tumor biology. Cancer Metastasis Rev 12: 303-324, 1993.

92. Marsano A, Maidhof R, Luo J, Fujikara K, Konofagou EE, Banfi A and Vunjak-Novakovic G: The effect of controlled expression of VEGF by transduced myoblasts in a cardiac patch on vascularization in a mouse model of myocardial infarction. Biomaterials 34: 393-401, 2013.

93. Aiello LP, Avery RL, Arrigg PG, Keyt BA, Jampel HD, Shah ST, Pasquale LR, Thieme H, Iwamoto MA, Park JE, et al: Vascular endothelial growth factor in ocular fluid of patients with diabetic retinopathy and other retinal disorders. N Engl J Med 331: 1480-1487, 1994.

94. Saharinen P, Eklund L and Alitalo K: Therapeutic targeting of the angiopoietin-TIE pathway. Nat Rev Drug Discov 16 635-661, 2017

95. Pugh CW and Ratcliffe PJ: Regulation of angiogenesis by hypoxia: Role of the HIF system. Nat Med 9: 677-684, 2003

96. Semenza GL: Targeting HIF-1 for cancer therapy. Nat Rev Cancer 38: 721-732, 2003.

97. Agrawal A, Gajghate S, Smith H, Anderson DG, Albert TJ, Shapiro IM and Risbud MV: Cited 2 modulates hypoxia-inducible factor-dependent expression of vascular endothelial growth factor in nucleus pulposus cells of the rat intervertebral disc. Arthritis Rheum 58: 3798-3808, 2008.

98. Ahn JK, Koh EM, Cha HS, Lee YS, Kim J, Bae EK and Ahn KS Role of hypoxia-inducible factor-1alpha in hypoxia-induced expressions of IL-8, MMP-1 and MMP-3 in rheumatoid fibroblast-like synoviocytes. Rheumatology (Oxford) 47: 834-839, 2008

99. Calvani M, Rapisarda A, Uranchimeg B, Shoemaker RH and Melillo G: Hypoxic induction of an HIF-1alpha-dependent bFGF autocrine loop drives angiogenesis in human endothelial cells. Blood 107: 2705-2712, 2006.

100. Bos R, van Diest PJ, de Jong JS, van der Groep P, van der Valk P and van der Wall E: Hypoxia-inducible factor-1alpha is associated with angiogenesis, and expression of bFGF, PDGF-BB, and EGFR in invasive breast cancer. Histopathology 46: 31-36, 2005

101. Wu M, Chen G and Li YP: TGF- $\beta$ and BMP signaling in osteoblast, skeletal development, and bone formation, homeostasis and disease. Bone Res 4: 16009, 2016.

102. Bian Q, Ma L, Jain A, Crane JL, Kebaish K, Wan M, Zhang Z, Edward Guo X, Sponseller PD, Séguin CA, et al Mechanosignaling activation of TGF $\beta$ maintains intervertebral disc homeostasis. Bone Res 5: 17008, 2017.

103. oshida S, Ono M, Shono T, Izumi H, Ishibashi T, Suzuki H and Kuwano M: Involvement of interleukin-8, vascular endothelial growth factor, and basic fibroblast growth factor in tumor necrosis factor alpha-dependent angiogenesis. Mol Cell Biol 17: 4015-4023, 1997.

104. Haro H, Kato T, Komori H, Osada M and Shinomiya K: Vascular endothelial growth factor (VEGF)-induced angiogenesis in herniated disc resorption. J Orthop Res 20: 409-415, 2002

105. Lee JM, Song JY, Baek M, Jung HY, Kang H, Han IB, Kwon YD and Shin DE: Interleukin-1 $\beta$ induces angiogenesis and innervation in human intervertebral disc degeneration. J Orthop Res 29 265-269, 2011

106. Sang Q: Complex role of matrix metal oproteinases in angiogenesis. Cell Res 8: 171-177, 1998.

107. Ebrahem Q and Anand A: Induction of angiogenesis by active matrix metalloproteinases-2 and 9: Role of VEGF. Invest Ophthalmol Vis Sci 44: 445-452, 2003.

108. Liang H, Xiao J, Zhou Z, Wu J, Ge F, Li Z, Zhang H, Sun J, Li F, Liu R and Chen C: Hypoxia induces miR-153 through the IRE1 $\alpha$-XBP1 pathway to fine tune the HIF1 $\alpha /$ VEGFA axis in breast cancer angiogenesis. Oncogene 37: 1961-1975, 2018.
109. Mazure NM, Brahimi-Horn MC and Pouysségur J: Protein kinases and the hypoxia-inducible factor-1, two switches in angiogenesis. Curr Pharm Des 9: 531-541, 2003.

110. Han IB, Ropper AE, Teng YD, Shin DA, Jeon YJ, Park HM, Shin DE, Park YS, Kim KN and Kim NK: Association between VEGF and eNOS gene polymorphisms and lumbar disc degeneration in a young Korean population. Genet Mol Res 12: 2294-2305, 2013

111. Long $\mathrm{H}$ and $\mathrm{Hu} \mathrm{Y}$ : Expression of vascular endothelial growth factor in lumbar intervertebral disc and its significance. Chin J Spinal Cord 12: 280-282, 2002.

112. Doita M, Kanatani T, Ozaki T, Matsui N, Kurosaka M and Yoshiya S: Influence of macrophage infiltration of herniated disc tissue on the production of matrix metalloproteinases leading to disc resorption. Spine (Phila Pa 1976) 26: 1522-1527, 2001.

113. Kobayashi S, Meir A, Kokubo Y, Uchida K, Takeno K, Miyazaki T, Yayama T, Kubota M, Nomura E, Mwaka E and Baba H: Ultrastructural analysis on lumbar disc herniation using surgical specimens: Role of neovascularization and macrophages in hernias. Spine (Phila Pa 1976) 34: 655-662, 2009.

114. Lu XY, Ding XH, Zhong LJ, Xia H, Chen XD and Huang H: Expression and significance of VEGF and p53 in degenerate intervertebral disc tissue. Asian Pac J Trop Med 6: 79-81, 2013.

115. Sánchez-Puig N, Veprintsev DB and Fersht AR: Binding of natively unfolded HIF-1alpha ODD domain to p53. Mol Cell 17: $11-21,2005$

116. Aubrey BJ, Kelly GL, Janic A, Herold MJ and Strasser A: How does p53 induce apoptosis and how does this relate to p53-mediated tumour suppression? Cell Death Differ 25: 104-113, 2018.

117. Luo W, Hu H, Chang R, Zhong J, Knabel M, O'Meally R, Cole RN, Pandey A and Semenza GL: Pyruvate kinase M2 is a PHD3-stimulated coactivator for hypoxia-inducible factor 1. Cell 145: 732-744, 2011.

118. Ullah K, Rosendahl AH, Izzi V, Bergmann U, Pihlajaniemi T, Mäki JM and Myllyharju J: Hypoxia-inducible factor prolyl-4-hydroxylase-1 is a convergent point in the reciprocal negative regulation of NF- $\mathrm{KB}$ and $\mathrm{p} 53$ signaling pathways. Sci Rep 7: 17220, 2017.

119. Chowdhury AR, Long A, Fuchs SY, Rustgi A and Avadhani NG: Mitochondrial stress-induced p53 attenuates HIF-1 $\alpha$ activity by physical association and enhanced ubiquitination. Oncogene 36: 397-409, 2017

120. Fujita N, Gogate SS, Chiba K, Toyama Y, Shapiro IM and Risbud MV: Prolyl hydroxylase 3 (PHD3) modulates catabolic effects of tumor necrosis factor- $\alpha(\mathrm{TNF}-\alpha)$ on cells of the nucleus pulposus through co-activation of nuclear factor $\kappa \mathrm{B}(\mathrm{NF}-\kappa \mathrm{B}) / \mathrm{p} 65$ signaling. J Biol Chem 287: 39942-39953, 2012 .

121. Johnson ZI, Schoepflin ZR, Choi H, Shapiro IM and Risbud MV: Disc in flames: Roles of TNF- $\alpha$ and IL- $1 \beta$ in intervertebral disc degeneration. Eur Cell Mater 30: 104-117, 2015.

122. Phillips KL, Cullen K, Chiverton N, Michael AL, Cole AA, Breakwell LM, Haddock G, Bunning RA, Cross AK and Le Maitre CL: Potential roles of cytokines and chemokines in human intervertebral disc degeneration: Interleukin-1 is a master regulator of catabolic processes. Osteoarthritis Cartilage 23: $1165-1177,2015$

123. Shen J, Xu S, Zhou H, Liu H, Jiang W, Hao J and Hu Z: IL-1 $\beta$ induces apoptosis and autophagy via mitochondria pathway in human degenerative nucleus pulposus cells. Sci Rep 7: 41067, 2017.

124. Shen J, Fang J, Hao J, Zhong X, Wang D, Ren H and $\mathrm{Hu} Z$ : SIRT1 inhibits the catabolic effect of IL-1 $\beta$ through TLR2/SIRT1/NF- $\kappa$ B pathway in human degenerative nucleus pulposus cells. Pain Physician 19: E215-E226, 2016.

125. Cheng X, Zhang L, Zhang K, Zhang G, Hu Y, Sun X, Zhao C, $\mathrm{Li} \mathrm{H}, \mathrm{Li}$ YM and Zhao J: Circular RNA VMA21 protects against intervertebral disc degeneration through targeting miR-200c and X linked inhibitor-of-apoptosis protein. Ann Rheum Dis 77: 770-779, 2018

126. Wang H, He P, Pan H, Long J, Wang J, Li Z, Liu H, Jiang W and Zheng Z: Circular RNA circ-4099 is induced by TNF- $\alpha$ and regulates ECM synthesis by blocking miR-616-5p inhibition of Sox9 in intervertebral disc degeneration. Exp Mol Med 50: 27, 2018.

127. Tian Y, Yuan W, Fujita N, Wang J, Wang H, Shapiro IM and Risbud MV: Inflammatory cytokines associated with degenerative disc disease control aggrecanase-1 (ADAMTS-4) expression in nucleus pulposus cells through MAPK and NF- $\kappa$ B. Am J Pathol 182: 2310-2321, 2013 
128. Wang H, Tian Y, Wang J, Phillips KL, Binch AL, Dunn S, Cross A, Chiverton N, Zheng Z, Shapiro IM, et al: Inflammatory cytokines induce NOTCH signaling in nucleus pulposus cells: Implications in intervertebral disc degeneration. J Biol Chem 288: 16761-16774, 2013

129. Cramer T, Yamanishi Y, Clausen BE, Förster I, Pawlinski R, Mackman N, Haase VH, Jaenisch R, Corr M, Nizet V, et al: HIF-1alpha is essential for myeloid cell-mediated inflammation. Cell 112: 645-657, 2003.

130. Oliver KM, Taylor CT and Cummins EP: Hypoxia. Regulation of NFkappaB signalling during inflammation: The role of hydroxylases. Arthritis Res Ther 11: 215, 2009.

131. Kapoor M, Martel-Pelletier J, Lajeunesse D, Pelletier JP and Fahmi H: Role of proinflammatory cytokines in the pathophysiology of osteoarthritis. Nat Rev Rheumatol 7: 33-42, 2011.

132. Malandrino A, Noailly J and Lacroix D: The effect of sustained compression on oxygen metabolic transport in the intervertebral disc decreases with degenerative changes. PLoS Comput Biol 7: e1002112, 2011

133. Mannello F and Medda V: Nuclear localization of matrix metalloproteinases. Prog Histochem Cytochem 47: 27-58, 2012.

134. Crean JK, Roberts S, Jaffray DC, Eisenstein SM and Duance VC: Matrix metalloproteinases in the human intervertebral disc: Role in disc degeneration and scoliosis. Spine (Phila Pa 1976) 22: 2877-2884, 1997.

135. Weiler C, Nerlich AG, Zipperer J, Bachmeier BE and Boos N: 2002 SSE award competition in basic science: Expression of major matrix metalloproteinases is associated with intervertebral disc degradation and resorption. Eur Spine J 11: 308-320, 2002.

136. Visse R and Nagase H: Matrix metalloproteinases and tissue inhibitors of metalloproteinases: Structure, function, and biochemistry. Circ Res 92: 827-839, 2003.

137. Xie Y, Mustafa A, Yerzhan A, Merzhakupova D, Yerlan P, N Orakov A, Wang X, Huang Y and Miao L: Nuclear matrix metalloproteinases: Functions resemble the evolution from the intracellular to the extracellular compartment. Cell Death Discov 3: 17036, 2017.

138. Kozaci LD, Guner A, Oktay G and Guner G: Alterations in biochemical components of extracellular matrix in intervertebral disc herniation: Role of MMP-2 and TIMP-2 in type II collagen loss. Cell Biochem Funct 24: 431-436, 2006.

139. Roberts S, Caterson B, Menage J, Evans EH, Jaffray DC and Eisenstein SM: Matrix metalloproteinases and aggrecanase: Their role in disorders of the human intervertebral disc. Spine (Phila Pa 1976) 25: 3005-3013, 2000

140. Rutges JP, Kummer JA, Oner FC, Verbout AJ, Castelein RJ, Roestenburg HJ, Dhert WJ and Creemers LB: Increased MMP-2 activity during intervertebral disc degeneration is correlated to MMP-14 levels. J Pathol 214: 523-530, 2008

141. Yurube T, Takada T, Suzuki T, Kakutani K, Maeno K, Doita M, Kurosaka M and Nishida K: Rat tail static compression model mimics extracellular matrix metabolic imbalances of matrix metalloproteinases, aggrecanases, and tissue inhibitors of metalloproteinases in intervertebral disc degeneration. Arthritis Res Ther 14: R51, 2012.

142. Séguin CA, Pilliar RM, Madri JA and Kandel RA: TNF-alpha induces MMP2 gelatinase activity and MT1-MMP expression in an in vitro model of nucleus pulposus tissue degeneration. Spine (Phila Pa 1976) 33: 356-365, 2008.

143. Xu YQ, Zhang ZH, Zheng YF and Feng SQ: Dysregulated miR-133a mediates loss of type II collagen by directly targeting matrix metalloproteinase 9 (MMP9) in human intervertebral disc degeneration. Spine (Phila Pa 1976) 41: E717-E724, 2016.

144. Hua WB, Wu XH, Zhang YK, Song Y, Tu J, Kang L, Zhao KC Li S, Wang K, Liu W, et al: Dysregulated miR-127-5p contributes to type II collagen degradation by targeting matrix metalloproteinase-13 in human intervertebral disc degeneration. Biochimie 139: 74-80, 2017.

145. Ji ML, Zhang XJ, Shi PL, Lu J, Wang SZ, Chang Q, Chen H and Wang C: Downregulation of microRNA-193a-3p is involved in invertebral disc degeneration by targeting MMP14. J Mol Med (Berl) 94: 457-468, 2016

146. Zhang WL, Chen YF, Meng HZ, Du JJ, Luan GN, Wang HQ, Yang MW and Luo ZJ: Role of miR-155 in the regulation of MMP-16 expression in intervertebral disc degeneration. J Orthop Res 35: 1323-1334, 2017.

147. Jung JC, Wang PX, Zhang G, Ezura Y, Fini ME and Birk DE: Collagen fibril growth during chicken tendon development: Matrix metalloproteinase-2 and its activation. Cell Tissue Res 336: 79-89, 2009.
148. Wang B, Ding YM, Fan P, Wang B, Xu JH and Wang WX: Expression and significance of MMP2 and HIF-1 $\alpha$ in hepatocellular carcinoma. Oncol Lett 8: 539-546, 2014.

149. Wu X, Liu W, Duan Z, Gao Y, Li S, Wang K, Song Y, Shao Z, Yang S and Yang C: The involvement of protease nexin-1 (PN1) in the pathogenesis of intervertebral disc (IVD) degeneration. Sci Rep 6: 30563, 2016.

150. Huang Z, Zhang L, Feng X, Chen T and Bi S: A new in vivo method to retard progression of intervertebral disc degeneration through stimulation of endogenous stem cells with simvastatin. Med Hypotheses 101: 65-66, 2017.

151. Lin Z, Weinberg JM, Malhotra R, Merritt SE, Holzman LB and Brosius FC III: GLUT-1 reduces hypoxia-induced apoptosis and JNK pathway activation. Am J Physiol Endocrinol Metab 278: E958-E966, 2000

152. Agrawal A, Guttapalli A, Narayan S, Albert TJ, Shapiro IM and Risbud MV: Normoxic stabilization of HIF-1alpha drives glycolytic metabolism and regulates aggrecan gene expression in nucleus pulposus cells of the rat intervertebral disk. Am J Physiol Cell Physiol 293: C621-C631, 2007.

153. Maher JC, Wangpaichitr M, Savaraj N, Kurtoglu M and Lampidis TJ: Hypoxia-inducible factor-1 confers resistance to the glycolytic inhibitor 2-deoxy-D-glucose. Mol Cancer Ther 6: $732-741,2007$.

154. Papandreou I, Cairns RA, Fontana L, Lim AL and Denko NC: HIF-1 mediates adaptation to hypoxia by actively downregulating mitochondrial oxygen consumption. Cell Metab 3: 187-197, 2006

155. Zhang H, Bosch-Marce M, Shimoda LA, Tan YS, Baek JH, Wesley JB, Gonzalez FJ and Semenza GL: Mitochondrial autophagy is an HIF-1-dependent adaptive metabolic response to hypoxia. J Biol Chem 283: 10892-10903, 2008.

156. Banh RS, Iorio C, Marcotte R, Xu Y, Cojocari D, Rahman AA, Pawling J, Zhang W, Sinha A, Rose CM, et al: PTP1B regulates non-mitochondrial oxygen consumption via RNF213 to promote tumour survival during hypoxia. Nat Cell Biol 18: 803-813, 2016.

157. Dutta D, Xu J, Kim JS, Dunn WA Jr and Leeuwenburgh C: Upregulated autophagy protects cardiomyocytes from oxidative stress-induced toxicity. Autophagy 9: 328-344, 2013.

158. Caramés B, Taniguchi N, Otsuki S, Blanco FJ and Lotz M Autophagy is a protective mechanism in normal cartilage, and its aging-related loss is linked with cell death and osteoarthritis. Arthritis Rheum 62: 791-801, 2010

159. Jiang L, Zhang X, Zheng X, Ru A, Ni X, Wu Y, Tian N, Huang Y, Xue E, Wang X and Xu H: Apoptosis, senescence, and autophagy in rat nucleus pulposus cells: Implications for diabetic intervertebral disc degeneration. J Orthop Res 31: 692-702, 2013.

160. Tu J, Li W, Li S, Liu W, Zhang Y, Wu X, Luo R, Hua W, Wang K, Song Y, et al: Sestrin-mediated inhibition of stress-induced intervertebral disc degradation through the enhancement of autophagy. Cell Physiol Biochem 45: 1940-1954, 2018.

161. Chen J, Xie JJ, Jin M, Gu YT, Wu CC, Guo WJ, Yan YZ, Zhang ZJ, Wang JL, Zhang XL, et al: Sirt6 overexpression suppresses senescence and apoptosis of nucleus pulposus cells by inducing autophagy in a model of intervertebral disc degeneration. Cell Death Dis 9: 56, 2018.

162. Chen D, Xia D, Pan Z, Xu D, Zhou Y, Wu Y, Cai N, Tang Q, Wang C, Yan M, et al: Metformin protects against apoptosis and senescence in nucleus pulposus cells and ameliorates disc degeneration in vivo. Cell Death Dis 7: e2441, 2016.

163. Gruber HE, Hoelscher GL, Ingram JA, Bethea S and Hanley EN Jr: Autophagy in the degenerating human intervertebral disc: In vivo molecular and morphological evidence, and induction of autophagy in cultured annulus cells exposed to proinflammatory cytokines-implications for disc degeneration. Spine (Phila Pa 1976) 40: 773-782, 2015

164. Mazure NM and Pouysségur J: Hypoxia-induced autophagy: Cell death or cell survival? Curr Opin Cell Biol 22: 177-180, 2010.

165. Scherz-Shouval R and Elazar Z: Regulation of autophagy by ROS: Physiology and pathology. Trends Biochem Sci 36: 30-38, 2011

166. Zhao Y, Chen G, Zhang W, Xu N, Zhu JY, Jia J, Sun ZJ, Wang YN and Zhao YF: Autophagy regulates hypoxia-induced osteoclastogenesis through the HIF-1 $\alpha / \mathrm{BNIP} 3$ signaling pathway. J Cell Physiol 227: 639-648, 2012.

167. Zhou J, Yao W, Li C, Wu W, Li Q and Liu H: Administration of follicle-stimulating hormone induces autophagy via upregulation of HIF-1 $\alpha$ in mouse granulosa cells. Cell Death Dis 8: e3001, 2017 
168. Ye W, Zhu W, Xu K, Liang A, Peng Y, Huang D and Li C: Increased macroautophagy in the pathological process of intervertebral disc degeneration in rats. Connect Tissue Res 54: 22-28, 2013

169. Choi H, Merceron C, Mangiavini L, Seifert EL, Schipani E, Shapiro IM and Risbud MV: Hypoxia promotes noncanonical autophagy in nucleus pulposus cells independent of MTOR and HIF1A signaling. Autophagy 12: 1631-1646, 2016.

170. Ding F, Shao Z-w and Xiong L-m: Cell death in intervertebral disc degeneration. Apoptosis 18: 777-785, 2013.

171. Gruber HE and Hanley EN Jr: Analysis of aging and degeneration of the human intervertebral disc. Comparison of surgical specimens with normal controls. Spine (Phila Pa 1976) 23: 751-757, 1998

172. Bakker WJ, Harris IS and Mak TW: FOXO3a is activated in response to hypoxic stress and inhibits HIF1-induced apoptosis via regulation of CITED2. Mol Cell 28: 941-953, 2007.

173. Fujita N, Imai J, Suzuki T, Yamada M, Ninomiya K, Miyamoto K, Iwasaki R, Morioka H, Matsumoto M, Chiba K, et al: Vascular endothelial growth factor-A is a survival factor for nucleus pulposus cells in the intervertebral disc. Biochem Biophys Res Commun 372: 367-372, 2008.

174. Huang S, Leung VY, Long D, Chan D, Lu WW, Cheung KM and Zhou G: Coupling of small leucine-rich proteoglycans to hypoxic survival of a progenitor cell-like subpopulation in rhesus macaque intervertebral disc. Biomaterials 34: 6548-6558, 2013.

175. Zeng Y, Danielson KG, Albert TJ, Shapiro IM and Risbud MV: HIF-1 alpha is a regulator of galectin-3 expression in the intervertebral disc. J Bone Miner Res 22: 1851-1861, 2007.

176. Silagi ES, Schoepflin ZR, Seifert EL, Merceron C, Schipani E, Shapiro IM and Risbud MV: Bicarbonate recycling by HIF-1-dependent carbonic anhydrase isoforms 9 and 12 is critical in maintaining intracellular $\mathrm{pH}$ and viability of nucleus pulposus cells. J Bone Miner Res 33: 338-355, 2018.

177. Guicheux J, Palmer G, Shukunami C, Hiraki Y, Bonjour JP and Caverzasio J: A novel in vitro culture system for analysis of functional role of phosphate transport in endochondral ossification. Bone 27: 69-74, 2000.

178. Hristova GI, Jarzem P, Ouellet JA, Roughley PJ, Epure LM, Antoniou J and Mwale F: Calcification in human intervertebral disc degeneration and scoliosis. J Orthop Res 29: 1888-1895, 2011.

179. Zaka R and Williams CJ: Role of the progressive ankylosis gene in cartilage mineralization. Curr Opin Rheumatol 18: 181-186, 2006.

180. Gurley KA, Reimer RJ and Kingsley DM: Biochemical and genetic analysis of ANK in arthritis and bone disease. Am J Hum Genet 79: 1017-1029, 2006.

181. Liu MH, Sun C, Yao Y, Fan X, Liu H, Cui YH, Bian XW, Huang B and Zhou Y: Matrix stiffness promotes cartilage endplate chondrocyte calcification in disc degeneration via miR-20a targeting ANKH expression. Sci Rep 6: 25401, 2016.

182. Sohn P, Crowley M, Slattery E and Serra R: Developmental and TGF-beta-mediated regulation of Ank mRNA expression in cartilage and bone. Osteoarthritis Cartilage 10: 482-490, 2002.
183. Zaka R, Dion AS, Kusnierz A, Bohensky J, Srinivas V, Freeman T and Williams CJ: Oxygen tension regulates the expression of ANK (progressive ankylosis) in an HIF-1-dependent manner in growth plate chondrocytes. J Bone Miner Res 24: 1869-1878, 2009.

184. Wang W, Deng G, Qiu Y, Huang X, Xi Y, Yu J, Yang X and Ye X: Transplantation of allogenic nucleus pulposus cells attenuates intervertebral disc degeneration by inhibiting apoptosis and increasing migration. Int J Mol Med 41: 2553-2564, 2018.

185. Sica A, Schioppa T, Mantovani A and Allavena P: Tumour-associated macrophages are a distinct M2 polarised population promoting tumour progression: Potential targets of anti-cancer therapy. Eur J Cancer 42: 717-727, 2006.

186. Liang G, Liu Z, Tan L, Su AN, Jiang WG and Gong C: HIF1 $\alpha$-associated circDENND4C promotes proliferation of breast cancer cells in hypoxic environment. Anticancer Res 37: 4337-4343, 2017.

187. Du WW, Yang W, Chen Y, Wu ZK, Foster FS, Yang Z, Li X and Yang BB: Foxo3 circular RNA promotes cardiac senescence by modulating multiple factors associated with stress and senescence responses. Eur Heart J 38: 1402-1412, 2017.

188. Serocki M, Bartoszewska S, Janaszak-Jasiecka A, Ochocka RJ, Collawn JF and Bartoszewski R: miRNAs regulate the HIF switch during hypoxia: A novel therapeutic target. Angiogenesis 21: 183-202, 2018.

189. Bao MH, Li GY, Huang XS, Tang L, Dong LP and Li JM: Long noncoding RNA LINC00657 acting as a miR-590-3p sponge to facilitate low concentration oxidized low-density lipoprotein-induced angiogenesis. Mol Pharmacol 93: 368-375, 2018.

190. Dang RY, Liu FL and Li Y: Circular RNA hsa_circ_0010729 regulates vascular endothelial cell proliferation and apoptosis by targeting the miR-186/HIF-1 $\alpha$ axis. Biochem Biophys Res Commun 490: 104-110, 2017.

191. Liu W, Zhang J, Zou C, Xie X, Wang Y, Wang B, Zhao Z, Tu J, Wang $\mathrm{X}, \mathrm{Li} \mathrm{H}$, et al: Microarray expression profile and functional analysis of circular RNAs in osteosarcoma. Cell Physiol Biochem 43: 969-985, 2017.

192. Guo W, Zhang B, Mu K, Feng SQ, Dong ZY, Ning GZ, Li HR, Liu S, Zhao L, Li Y, et al: Circular RNA GRB10 as a competitive endogenous RNA regulating nucleus pulposus cells death in degenerative intervertebral disk. Cell Death Dis 9: 319, 2018

193. Pfirrmann CW, Metzdorf A, Zanetti M, Hodler J and Boos N: Magnetic resonance classification of lumbar intervertebral disc degeneration. Spine (Phila Pa 1976) 2: 1873-1878, 2001.

194. Martin JT, Gorth DJ, Beattie EE, Harfe BD, Smith LJ and Elliott DM: Needle puncture injury causes acute and long-term mechanical deficiency in a mouse model of intervertebral disc degeneration. J Orthop Res 31: 1276-1282, 2013.

195. Kulcheski FR, Christoff AP and Margis R: Circular RNAs are miRNA sponges and can be used as a new class of biomarker. J Biotechnol 238: 42-51, 2016

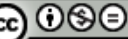

This work is licensed under a Creative Commons Attribution-NonCommercial-NoDerivatives 4.0 International (CC BY-NC-ND 4.0) License. 